\title{
Pericytes of human skeletal muscle are myogenic precursors distinct from satellite cells
}

\author{
Arianna Dellavalle ${ }^{1,12}$, Maurilio Sampaolesi ${ }^{1,2,12}$, Rossana Tonlorenzi ${ }^{1}$, Enrico Tagliafico ${ }^{3}$, Benedetto Sacchetti ${ }^{4}$, \\ Laura Perani ${ }^{1}$, Anna Innocenzi ${ }^{1}$, Beatriz G. Galvez ${ }^{1}$, Graziella Messina ${ }^{1,5}$, Roberta Morosetti ${ }^{6}$, Sheng Li ${ }^{7}$, \\ Marzia Belicchi ${ }^{8}$, Giuseppe Peretti ${ }^{1}$, Jeffrey S. Chamberlain ${ }^{7}$, Woodring E. Wright ${ }^{9}$, Yvan Torrente ${ }^{8}$, \\ Stefano Ferrari ${ }^{3}$, Paolo Bianco ${ }^{4,10}$ and Giulio Cossu ${ }^{1,4,11,13}$
}

Cells derived from blood vessels of human skeletal muscle can regenerate skeletal muscle, similarly to embryonic mesoangioblasts. However, adult cells do not express endothelial markers, but instead express markers of pericytes, such as NG2 proteoglycan and alkaline phosphatase (ALP), and can be prospectively isolated from freshly dissociated ALP+ cells. Unlike canonical myogenic precursors (satellite cells), pericyte-derived cells express myogenic markers only in differentiated myotubes, which they form spontaneously with high efficiency. When transplanted into severe combined immune deficient-X-linked, mouse muscular dystrophy $(s c i d-m d x)$ mice, pericyte-derived cells colonize host muscle and generate numerous fibres expressing human dystrophin. Similar cells isolated from Duchenne patients, and engineered to express human mini-dystrophin, also give rise to many dystrophin-positive fibres in vivo. These data show that myogenic precursors, distinct from satellite cells, are associated with microvascular walls in the human skeletal muscle, may represent a correlate of embryonic 'mesoangioblasts' present after birth and may be a promising candidate for future cell-therapy protocols in patients.

Satellite cells embody the main myogenic activity in adult muscle ${ }^{1-3}$, but lack the ability to cross the muscle endothelium when delivered systemically, and because of this limited migration, they must be injected intra-muscularly every $2 \mathrm{~mm}^{3}$ of the patient's muscles ${ }^{4}$. Furthermore, the large majority of injected cells are lost within the first day ${ }^{5}$. Additional problems include the reduced proliferation potency of satellite cells from dystrophic patients and the recent observation that in vitro expansion reduces in vivo differentiation potency ${ }^{6}$.

The demonstration that other cell types can differentiate into skeletal muscle in vitro or in $v i v{ }^{7}$ has created an alternative possibility for the cell therapy of muscular dystrophy. In this context, the identification of myogenic precursors in the wall of the embryonic dorsal aorta in birds and rodents suggested that similar cells could be found in human postnatal microvascular walls ${ }^{8}$.

From a strictly applicative point of view, the ideal cell population should be: present in easily accessible postnatal tissues; expandable in vitro to the large number of cells presumably required for systemic treatment $\left(1 \times 10^{9}\right.$ or more); easily transducible with viral vectors; able to reach skeletal muscle through a systemic route; and should be able to differentiate into skeletal muscle cells in vivo with high efficiency. Here, we isolate and characterize parietal cells from the microvasculature of human skeletal-muscle cells, and show that they fulfill all these criteria.

\section{RESULTS}

Isolation and in vitro expansion of cells from muscle biopsies Ten biopsies from non-dystrophic patients and six from Duchenne muscular dystrophy (DMD) patients, ranging in age from 15-78 years (non-DMD) and 3-8 years (DMD) were used in this study. Fragments of interstitial tissue containing vessels were dissected and plated on collagen-coated dishes. After the initial outgrowth of fibroblasts, small round and refractile cells were observed (Fig. 1a) that adhered poorly to the substratum, and these were collected by gentle pipetting. On average, $1 \times 10^{4}$ cells (arbitrarily counted as population doubling 2 ) were isolated from a fragment of tissue weighing approximately $200 \mathrm{mg}$. When grown in standard media that supports proliferation of satellite cells or mesenchymal stem cells, these cells rapidly (within two passages) enter

${ }^{1}$ Stem Cell Research Institute, San Raffaele Scientific Institute, 58 Via Olgettina, 20132 Milan, Italy. ${ }^{2}$ Department of Experimental Medicine, University of Pavia, 6 Via Forlanini, 27100 Pavia, Italy. ${ }^{3}$ Department of Biomedical Sciences, University of Modena and Reggio Emilia, 287 Via Campi, 41100 Modena, Italy. ${ }^{4}$ Institute of Cell Biology and Tissue Engineering, San Raffaele Biomedical Science Park, 100/2 Via Castel Romano, 00128 Rome, Italy. ${ }^{5}$ Department of Cellular and Developmental Biology, University of Rome La Sapienza, 5 Piazza Aldo Moro, 00161 Rome, Italy. ${ }^{6}$ Department of Neurology, Catholic University, 8 Largo A. Gemelli, 00168 Rome, Italy. ${ }^{7}$ Department of Neurology, University of Washington, 1959 N.E. Pacific Street, Seattle, WA 98195-7720. USA. ${ }^{8}$ Department of Neurological Science, Ospedale

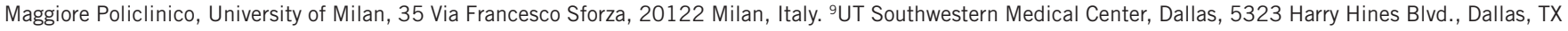
75390-9039, USA. ${ }^{10}$ Department of Experimental Pathology, University of Rome La Sapienza, 324 Via Regina Elena, 00161 Rome, Italy. ${ }^{11}$ Department of Biology, University of Milan, 26 Via Celoria, 20130 Milan, Italy. ${ }^{12}$ These authors contributed equally to this work.

${ }^{13}$ Correspondence should be addressed to G.C. or P.B. (e-mail: cossu.giulio@hsr.it; p.bianco@flashnet.it) 

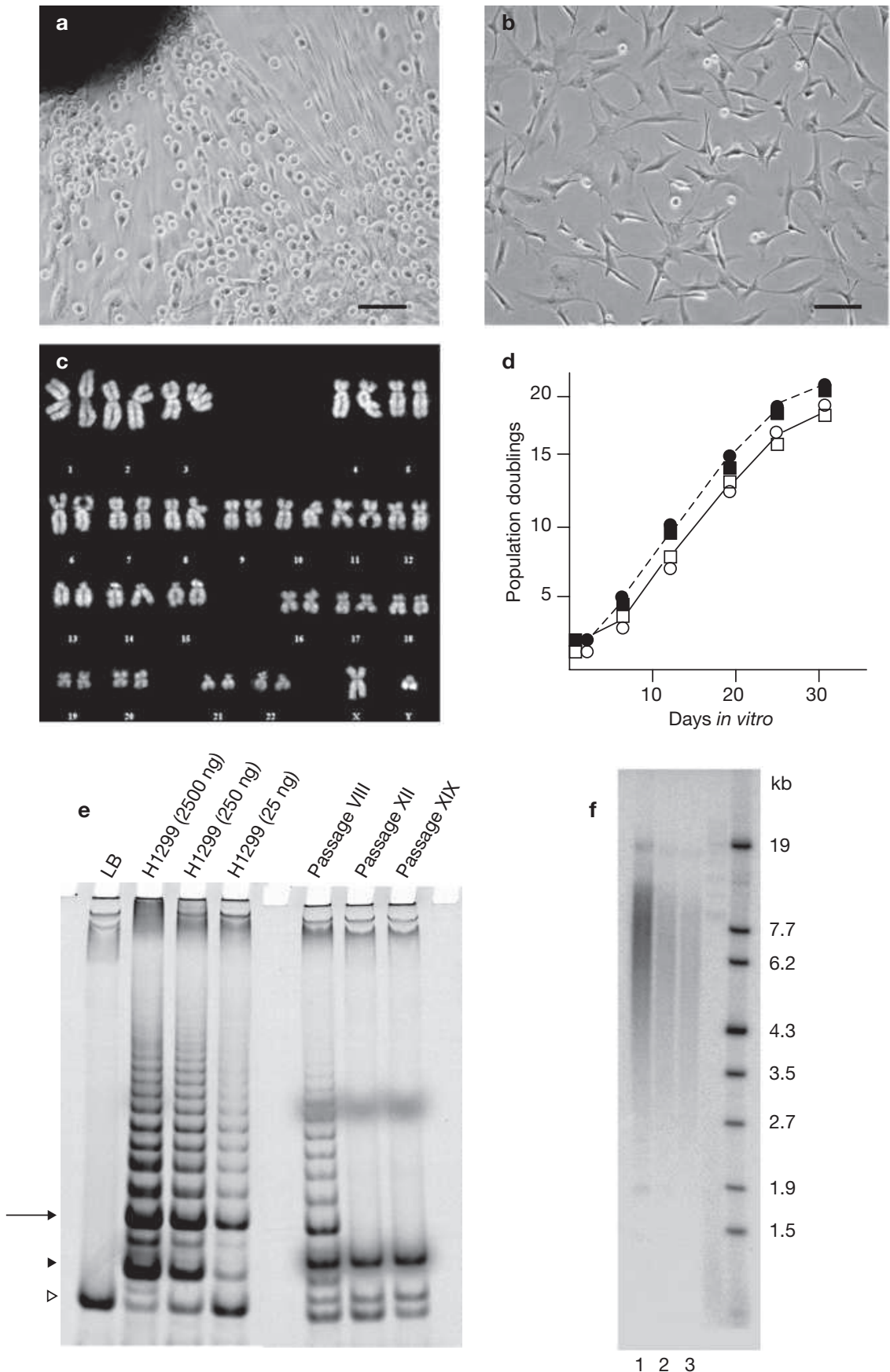

Figure 1 In vitro characterization of human adult interstitial cells. (a) Phasecontrast morphology of the cellular outgrowth of a fragment of interstitial tissue containing a small vessel cultured from a biopsy of normal adult human muscle. Round and refractile cells are visible on top of a layer of fibroblast-like cells. (b) Phase-contrast morphology of a polyclonal population isolated from an explant culture after 5 passages in vitro. (c) Karyotype of human interstitial cells after 15 passages, showing an euploid number of chromosomes. (d) Proliferation curves of two different normal (open symbols) and two dystrophic (closed symbols) cell populations. (e) Telomerase

senescence. However, a culture system was devised (see Methods) in which most cells maintained a triangular, refractile morphology (Fig. 1b) and a high proliferation rate for approximately 20 population doublings, with a doubling time of approximately $36 \mathrm{~h}$ (Fig. 1d). The proliferation rate was largely independent of donor age, although initially more cells outgrew activity of human adult interstitial cells at passage VIII, XII and XIX. Human carcinoma cells, HI299, are also shown as a positive control. Amount of protein extract is indicated. The arrow indicates the first ladder of polymerase addition product; the black arrowhead shows non-specific amplification products present in all samples; the white arrowhead shows the internal TRAP assay standard, used as a semi-quantitative reference band. LB, negative control. (f) Average telomere length from cells at passage VIII, XII and XIX (lanes 1, 2 and 3, respectively) showing progressive shortening. The scale bars represent $10 \mu \mathrm{m}$ in $\mathbf{a}$ and $\mathbf{b}$.

from explants of young DMD patients. Using in vitro expansion, approximately $2 \times 10^{9}$ cells were obtained from $1 \times 10^{4}$ culture-initiating cells. This number may be suitable for intra-arterial delivery in young patients, based on a per kg comparison with the mouse model used previously ${ }^{9}$. After 20 population doublings, large flat cells were observed at increasing frequency 
and the whole population rapidly underwent senescence. At both early and late passages, cells maintained a diploid karyotype (Fig. 1c). Early passage (passage VIII) cells showed a significant telomerase activity (telomeric repeats amplification protocol, TRAP, approximately 5-10\% that found in H1299 reference cancer cells (Fig. 1e). At later passages, telomerase activity was no longer detected, thus explaining the occurrence of proliferative senescence. Consistently, telomere length progressively shortened and by passage XIX had reached a size typical of presenescent cells (Fig. 1f). To examine tumorigenicity, $1 \times 10^{7}$ human cells were injected subcutaneously into 10 nude and 10 SCID mice, which were then maintained up to 12 months after the injection with no visible tumour detectable at autopsy (data not shown). When similar cells were derived from biopsies of Duchenne patients, they showed identical morphology and culture behaviour (Fig. 1d and data not shown).

\section{Phenotype of human adult muscle interstitial cells}

Gene expression profiling, on Affymetrix chips, of two polyclonal populations of cells from biopsies of normal individuals and two from Duchenne patients, revealed that these cells express pericyte markers (annexin V, alkaline phosphatase, desmin, smooth muscle actin, vimentin and PDGF receptor $\beta$ ) at high levels ${ }^{10}$; however, they do not express $\mathrm{M}$-cadherin, N-CAM, cytokeratins or neurofilaments (with the exception of nestin), or endothelial markers (such as CD31, CD34 and KDR). Immunocytochemistry, RT-PCR and western blot analysis on cultured cells confirmed the results from microarray analysis (Fig. 2a-h). Clones from one of these populations also expressed these markers in the same percentage (approximately $20 \%$ of the population expressed smooth muscle actin (SMA) or desmin, 50\% expressed neural-glial-2 chondroitin sulphate proteglycan (NG2) and more than 90\% expressed PDGFR $\beta$ ), which did not vary at successive passages (data not shown). Of note, myogenic markers (MyoD, Myf5 and Myogenin) expressed in cultures of myogenic precursors were not expressed in these cells, as assessed by array analysis or RT-PCR (Fig. 2g), with the possible exception of Pax3, which was expressed by both populations at very low levels.

When the expression of surface antigens was determined, pericyte-like cells were: uniformly negative for CD31, CD34, CD45, CD62L, CD71, CD106, CD117 and CD133; weakly positive for CD49b, CD63, CD90, CD105 and CD146; and strongly positive for CD13 and CD44 (Fig. $2 \mathrm{i}$ and data not shown). All these results are in agreement with data from microarray analysis (data not shown).

In culture, cells obtained from DMD patients were indistinguishable from cells derived from normal muscle for all of the parameters described above, and microarray analysis highlighted only a small number of genes that are differentially expressed (Fig. 2j and see Supplementary Information, Fig. S1). Some inflammatory genes seemed to be upregulated in DMD cells, whereas few genes (such as Ephrin B2 and $\alpha$ tropomyosin) were expressed at higher levels in normal cells; however, the significance of these observations is unclear. Notably, two normal polyclonal populations (Fig. $2 \mathrm{j}$ lanes 3,4 ) and two clones from one of these populations (lanes 5,6) all expressed similar profiles, further demonstrating the homogeneity of the cell population selected by the explant culture method.

\section{Prospective isolation of pericytes from skeletal muscle}

When studying bone morphogenic protein-2 (BMP-2)-induced osteogenic differentiation, all human cells selected by our culture conditions expressed ALP, and also expressed ALP in the absence of BMP-2 (Fig. 3a). Futhermore, the small round cells that outgrew from the primary explant also expressed ALP (inset in Fig. 3a). In adult skeletal muscle, only vessels are known to be positive for ALP ${ }^{11}$ (Fig. 3b). Double staining for the endothelial marker CD31 (PECAM) and ALP clearly showed ALP-positive (blue) cells adjacent to the endothelium (brown) as typical pericytes (Fig. 3c). Pericytes and satellite cells were localized in vivo in their specific anatomical locations. Fig. 3d shows a triple-stained section of human normal skeletal muscle: satellite cells (green, anti-M cadherin antibody) were located underneath the fibre basal lamina (magenta, anti-laminin antibody), whereas pericytes (red, anti-ALP antibody) were localized underneath the vessel basal lamina. This localization was confirmed by confocal microscopy (Fig. 3e), showing fluorescent images superimposed on a phase-contrast image of normal adult skeletal muscle, where $\mathrm{ALP}^{+}$cells (magenta) were adjacent to $\mathrm{CD} 31^{+}$cells (green), but were clearly separated from the $\mathrm{M}-\mathrm{Cad}^{+}$ (red) cells. These observations strongly suggest that the human cells that we expanded in culture were derived from pericytes. To formally demonstrate this hypothesis, biopsies of human normal skeletal muscle (from individuals aged 25 and 46 years) were enzymatically digested to a single-cell population that was separated by a fluorescence activated cell sorter according to the expression of ALP and CD56 (recognizing $\mathrm{N}$-CAM, which is expressed in satellite cells, but not in pericytes). The $\mathrm{ALP}^{+}-\mathrm{CD} 56^{-}$fraction accounted for $2-4 \%$ of the total population in two separate experiments, wheras the $\mathrm{ALP}^{-}-\mathrm{CD}^{2} 6^{+}$fraction accounted for 9$11 \%$. In both experiments, the double-positive fraction $\left(\mathrm{ALP}^{+}-\mathrm{CD} 56^{+}\right)$ represented less than $0.1 \%$ of the total population (Fig. 4a), suggesting that cells coexpressing pericyte and satellite cell markers are rare in vivo. After sorting, both $\mathrm{ALP}^{+}-\mathrm{CD}^{-} 6^{-}$and $\mathrm{ALP}^{-}-\mathrm{CD} 56^{+}$fractions were cloned by limiting dilution, and the number and phenotype of growing clones was evaluated after 5 days (data not shown) or 2 weeks (Fig. 4b-f). More than $90 \%$ of newly developing clones from the $\mathrm{ALP}^{+}-\mathrm{CD}^{-} 6^{-}$fraction (at 5 days) expressed ALP, but did not express Myf5. In contrast, the large majority (>80\%) of clones from $\mathrm{ALP}^{-}-\mathrm{CD} 56^{+}$fraction expressed Myf5, but not ALP. A minority of clones did not express either Myf5 or ALP, and are likely to represent fibroblasts (data not shown). After two weeks, the majority of clones derived from the $\mathrm{ALP}^{+}-\mathrm{CD} 56^{-}$fraction expressed ALP, but not Myf5 (Fig. 4b). These clones also expressed SMA and PDGFR $\beta$ (data not shown), similarly to bona fide pericytes. However, some clones seemed heterogeneous, with cells expressing ALP or Myf5 in variable proportions (20-60\% and $10-30 \%$ of the cells, respectively), and rarely expressed both markers in the same cell. Other clones were observed at this time that did not express either ALP or Myf5 (likely to be fibroblasts). On the contrary, the majority of clones from the $\mathrm{ALP}^{-}-\mathrm{CD}^{-} 6^{+}$fraction seemed to express Myf5 and not ALP, similarly to myogenic precursors (Fig. 4c), whereas other clones from this fraction did not express either marker (fibroblasts). Also in this fraction, a significant number of clones expressed both Myf5 and ALP in different cells and in some case in the same cell (Fig. 4d). A quantitative analysis of this experiment is shown in Fig. 4g. The nature of the heterogeneous clones has yet to be explained. In polyclonal cultures of satellite cells, ALP-expressing cells have been observed ${ }^{12}$. However, polyclonal populations of $\mathrm{ALP}^{+}$pericyte-derived cells never expressed MyoD or Myf5 at detectable level, unless myogenic differentiation was triggered. Clonal conditions may induce myogenic differentiation in a fraction of the clone, but this has yet to be tested. Nevertheless, the cloning experiments 

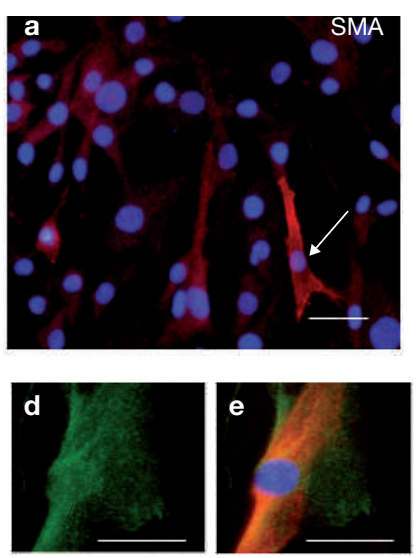

h
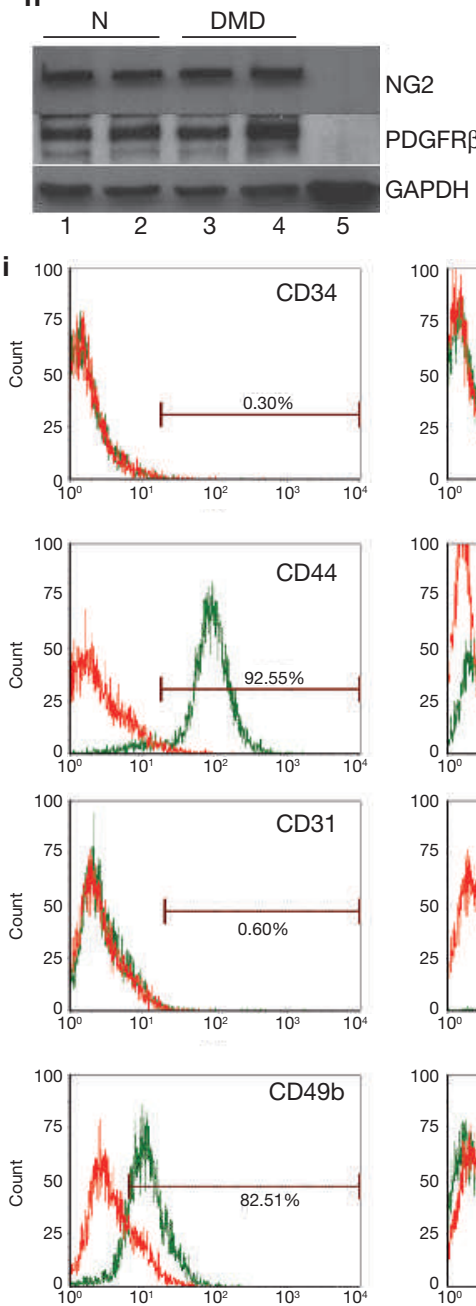
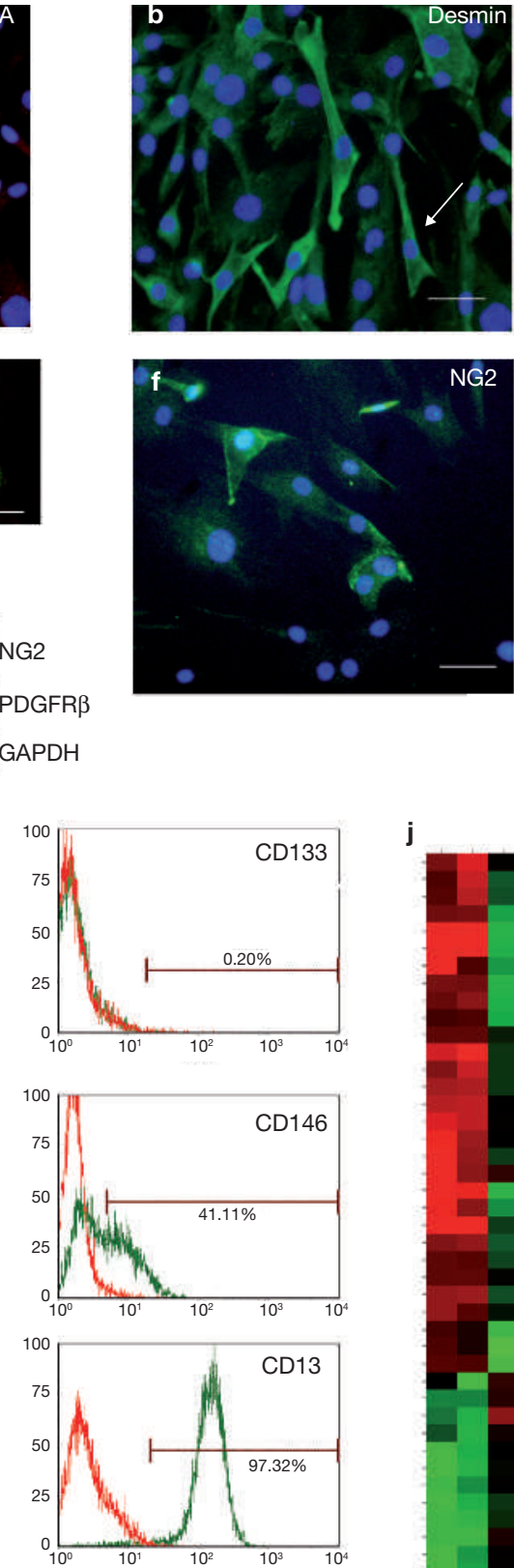

DGFR $\beta$

APDH

j

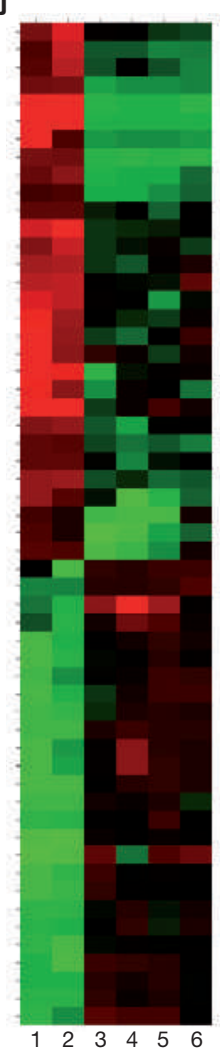

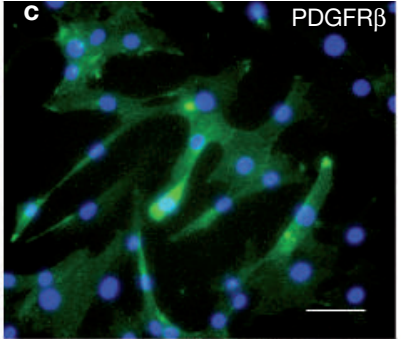

g

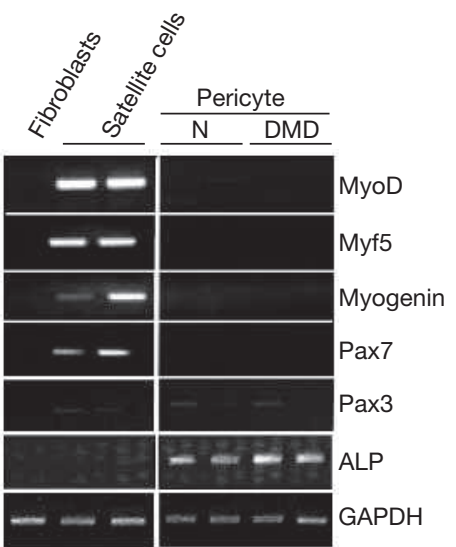

Figure 2 Phenotype of human adult pericyte-derived cells.

(a-f) Immunofluorescence microscopy analysis with anti-SMA (a) and anti-desmin (b) antibodies, indicating expression in approximately $10 \%$ of the population. In some cases, the cells coexpress these two markers (arrows). An anti-PDGFR $\beta$ (c) stains the majority of the cells at the cell surface, as detailed in $\mathbf{d}$ and $\mathbf{e}$ (which also shows costaining with anti-SMA) and anti-NG2 (f). Nuclei are stained with DAPI. (g) RT-PCR analysis of the expression of MyoD, Myf5, Myogenin, Pax7, Pax3 and ALP in human fibroblasts, satellite cells, normal (N) and DMD pericytes. Control GAPDH is also shown. (h) Western blot analysis of NG2 proteoglycan and PDGFR $\beta$ in extracts from pericytes isolated from normal (lanes 1,2) and DMD (lanes 3, 4) muscle. Human normal muscle extract is also shown (lane 5) as a negative control. GAPDH is shown for sample normalization. (i) FACS analysis of human pericyte-derived cells using a panel of $C D$ antibodies (CD34, CD133, CD44, CD146, CD31, CD13, CD49b and CD45).

(j) Microarray analysis showing significant genes differentially expressed between DMD (lanes 1, 2) and normal (lanes 3, 4) polyclonal populations of pericyte-derived cells. Lanes 5 and 6 show the profile of differentially expressed genes in two individual clones from the polyclonal population shown in lane 3 . The scale bars represent $20 \mu \mathrm{m}$ in a-f. 

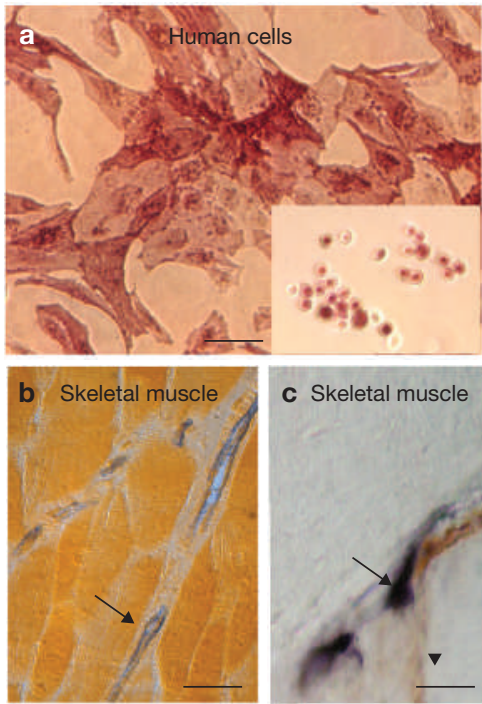

c Skeletal muscle
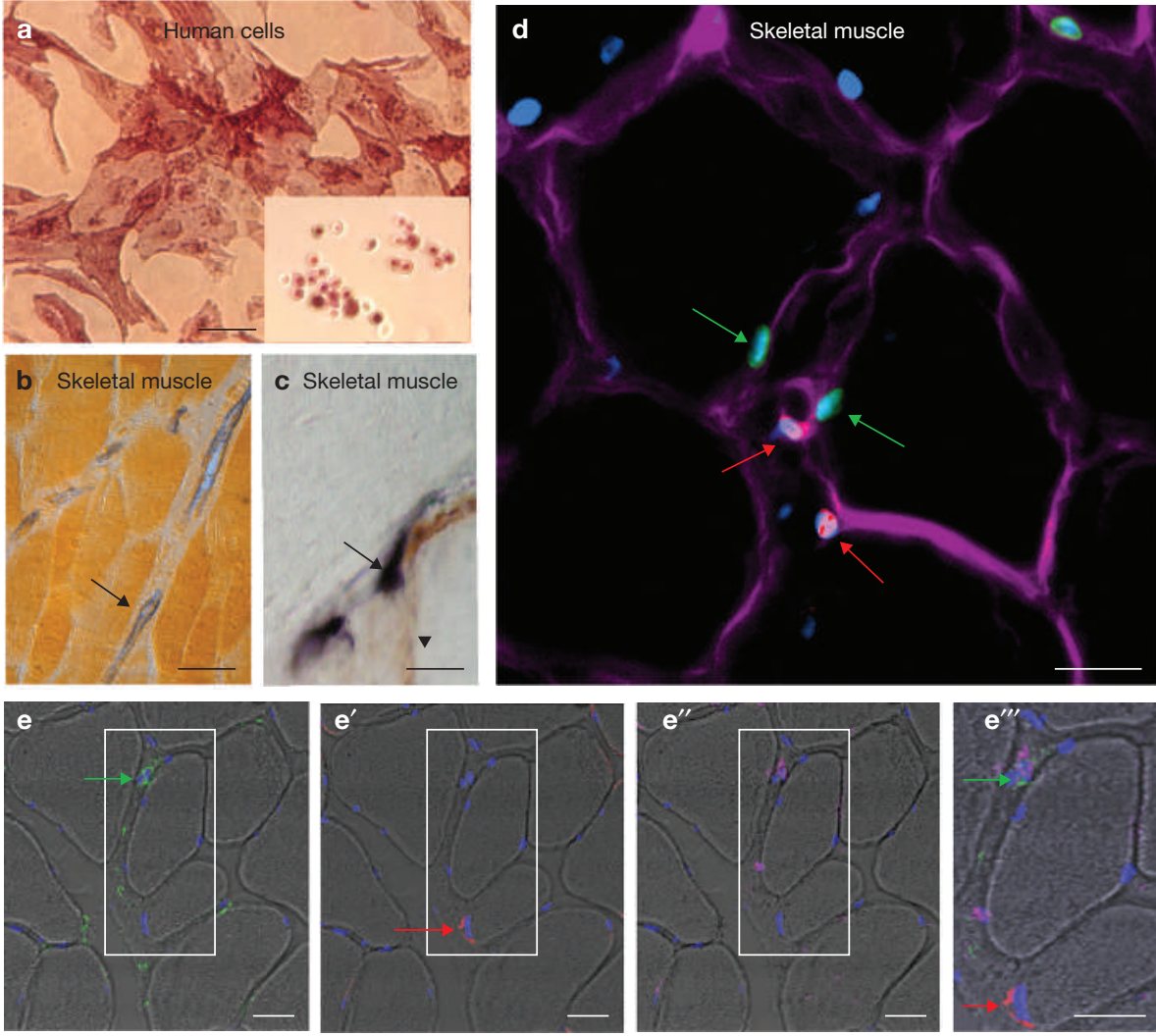

Figure 3 ALP activity in interstitial cells and muscle tissue. (a) Staining for ALP indicates expression at varying levels in most of cells outgrown from explants. The inset shows floating cells, just removed from the explant shown in Fig. 1a, all of which also express ALP. (b) ALP activity in human normal muscle, indicating expression in small vessels (arrow) of the interstitial tissue. (c) Double staining of human normal muscle with an antibody against PECAM, revealed by peroxidase staining in brown (arrowhead), and with enzymatic reaction for ALP staining in purple (arrow). An endothelial cell (arrowhead) is associated with a pericyte (arrow). (d) Immunofluorescence

indicate that human muscle pericytes can be prospectively isolated and can give rise to clones that maintain expression of a pericyte phenotype. As described below, pericyte-derived cells can differentiate into skeletal muscle. Therefore, we selected 10 clones from the $\mathrm{ALP}^{+}-\mathrm{CD}_{56}{ }^{-}$fraction and 10 from the $\mathrm{ALP}^{-}-\mathrm{CD}_{5} 6^{+}$fraction for in vitro expansion. Part of each clone was stained for ALP activity and Myf5 expression, and part was induced to differentiate. Six out of $10 \mathrm{ALP}^{+}-\mathrm{CD}^{-} 6^{-}$clones and 10 out of $10 \mathrm{ALP}^{-}-\mathrm{CD}_{5} 6^{+}$clones differentiated into myotubes when exposed to low-serum medium (examples of myogenic differentiation in one clone derived from each fraction are shown in Fig. 4e, f).

\section{In vitro differentiation}

$\mathrm{ALP}^{+}-\mathrm{CD} 56^{-}$, pericyte-derived cells differentiate into smooth muscle, osteoblasts or adipocytes after appropriate stimuli (data not shown). When skeletal-muscle differentiation was induced by coculturing $\mathrm{n}$ LacZ labelled human adult pericyte-derived cells with mouse myogenic cells, a very high percentage (more than 50\%) of $\mathrm{LacZ}^{+}$nuclei fused into hybrid myotubes (Fig. 5a, b) that expressed human MyoD (Fig. 5g). Moreover, when exposed to muscle-differentiation medium, a large proportion (ranging between 20 and $40 \%$ in different experiments) of human adult pericyte-derived cells spontaneously differentiated into microscopy of human normal muscle stained with antibodies against Mcadherin recognizing satellite cells (green arrows), laminin (magenta) and ALP (red) recognizing pericytes (red arrows). Nuclei are stained in blue with DAPI. (e-e'"') Immunofluorescence microscopy of human normal muscle stained with antibodies against CD31 (e, green), M-cadherin ( $\mathbf{e}^{\prime}$, red) and ALP ( $\mathbf{e}^{\prime \prime}$, magenta). A merged image is shown in $\mathbf{e}^{\prime \prime \prime}$. Nuclei are stained in blue with DAPI. All the images are superimposed on a phase-contrast image showing human muscle fibres and interstitial tissue. The scale bars represent $20 \mu \mathrm{m}$ in all panels.

myosin-positive multinucleated myotubes. No significant differences were observed between cells from normal or DMD muscle (Fig. 5c, d). Under similar conditions, approximately $60 \%$ of the myogenic cells derived from normal satellite cells differentiated into multinucleated myotubes (Fig. 5e). A quantitative analysis of these data is shown in Fig. 5f. The morphological analysis was confirmed by western blot analysis, showing expression of sarcomeric myosin heavy chains in these cultures (Fig. 5h). This result indicates a high skeletal myogenic potential for human pericyte derived cells. We then investigated the kinetics of differentiation by measuring the expression of Pax7, Myf5, MyoD, Myogenin and Myosin heavy chains in cells sorted for the expression of CD56 or ALP (Fig. 6a). Pericyte derived cells (Fig. 6b'), at variance with satellite cell-derived myogenic precursors (Fig. 6b), never expressed Pax7, Myf5 or MyoD during the proliferation phase (Fig. 6d, Day 3 and data not shown), but activated them at the onset of terminal differentiation. The activation was simultaneous with myogenin (Fig. 6d, Day 5) and shortly before the accumulation of myosin heavy chains in myotubes (Fig. 6d, Day 7). Interestingly almost all $\mathrm{MyoD}^{+}$nuclei were inside myosin heavy chain-positive myotubes. These data were quantified in Fig. 6c. In contrast, satellite cell-derived myogenic precursors already expressed Myf5 and Pax7 at the onset of the culture (Fig. 6f, Day 1) 

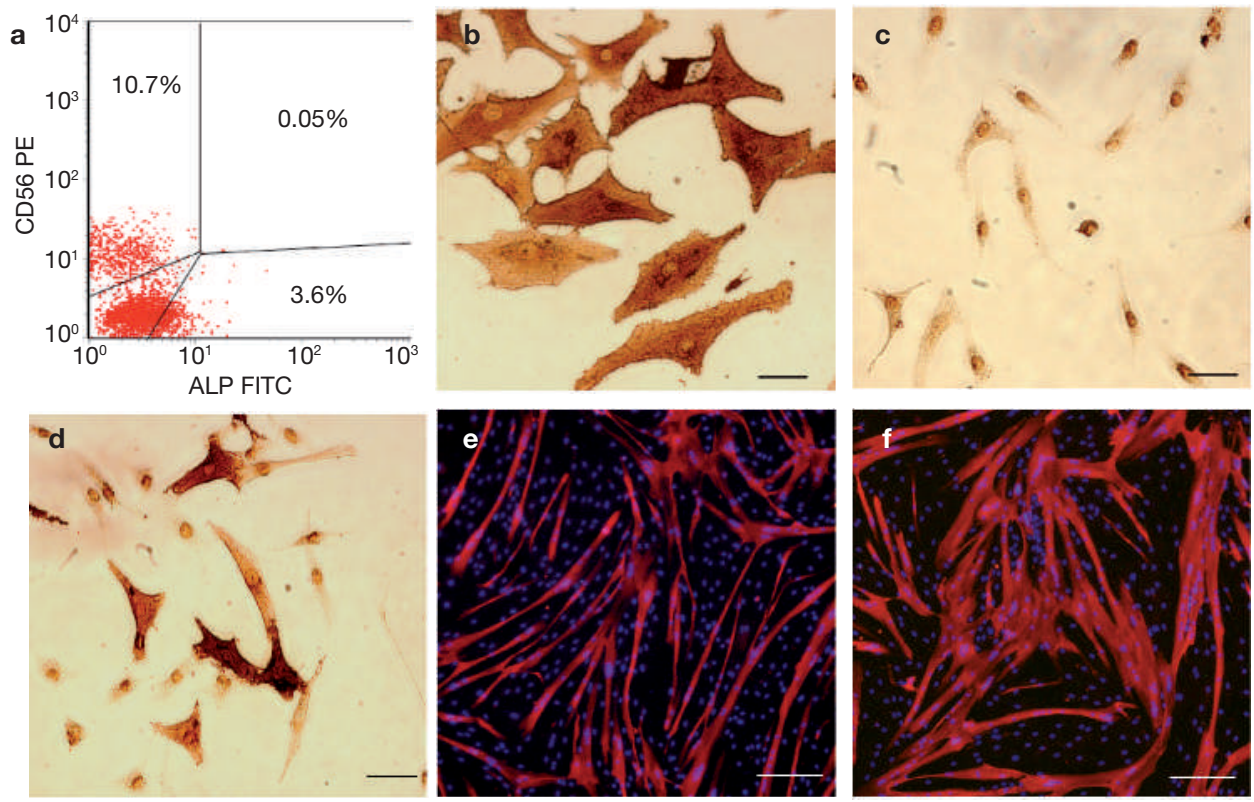

g

$\mathrm{ALP}^{+}-\mathrm{CD}^{-} 6^{-}$fraction

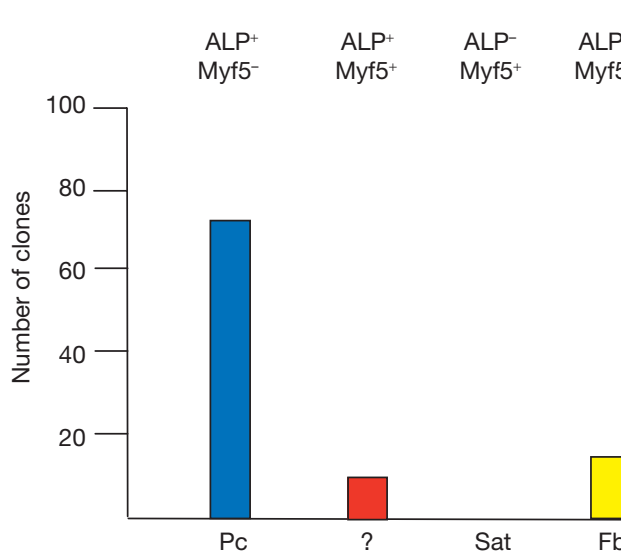

$\mathrm{ALP}^{-}-\mathrm{CD} 56^{+}$fraction

$\mathrm{ALP}^{+} \quad \mathrm{ALP}^{-} \quad \mathrm{ALP}^{-}$ $\mathrm{Myf5}^{+} \mathrm{Myf5}^{+} \quad \mathrm{Myf5}^{-}$

Figure 4 Clonal analysis of cells isolated from muscle. (a) Isolation of ALP- and CD56-positive cells from freshly dissociated human muscle. $\mathrm{ALP}^{+}$cells (3.6\% of the total population) were separated from $\mathrm{CD}^{2} 6^{+}$cells (10.7\%) by FACS. (b) An ALP+-Myf5- clone derived from the ALP+-CD56 fraction of total muscle stained for ALP (cytoplasmic staining) and with an anti-Myf5 antibody, revealed by peroxidase. (c) An ALP--Myf5+ clone derived from the ALP- $-\mathrm{CD} 56^{+}$fraction of total muscle stained for ALP and with an anti-Myf5 antibody (nuclear staining after peroxidase-conjugated second antibody). (d) An $\mathrm{ALP}^{+}-\mathrm{Myf5}^{+}$clone from the $\mathrm{ALP}^{+}-\mathrm{CD} 56^{-}$fraction

and activated myogenin before myosin heavy chain (Fig. 6f, Day3). Furthermore, when myosin heavy chain-positive myotubes had developed, many $\mathrm{MyoD}^{+}$-myosin heavy chain-negative cells were still present in the culture (Fig. 6f, Day 5). These data were quantified in Fig. 6e.

\section{In vivo studies}

We then examined the myogenic potency of human pericyte-derived cells in scid-mdx, immunodeficient mice. When injected into the femoral artery of female $s c i d-m d x$ dystrophic mice ${ }^{13}$, male human adult cells or murine embryonic mesoangioblasts colonized downstream muscle. After $24 \mathrm{~h}$ quantitative PCR for the Y chromosome revealed that approximately $10 \%$ of injected cells (both murine and human) could stained for ALP and with an anti-Myf5 antibody. A cell expressing both markers is indicated by the arrow. (e, f) Skeletal muscle differentiation of an $\mathrm{ALP}^{+-} \mathrm{CD}^{-} 6^{-}$(e) and of an $\mathrm{ALP}^{-}-\mathrm{CD}^{-} 6^{+}$clone (f), after two weeks in culture, followed by an additional week in low-serum differentiation medium. Cells were stained with MF20 anti-sarcomeric myosin antibody (red) and DAPI. (g) Total number of clones from the ALP+-CD56- and ALP-CD56+ fractions, stained after 15 days for ALP and Myf5. Pc, pericytederived cells; ?, cells with undefined phenotype; Sat, satellite cells; Fb, fibroblasts. The scale bars represent $20 \mu \mathrm{m}$ in $\mathbf{b}-\mathbf{d}$ and $50 \mu \mathrm{m}$ in $\mathbf{e}$ and $\mathbf{f}$.

be detected in downstream muscles and less than $1 \%$ in contra-lateral muscles, with the remaining cells being localized mainly in filter organs (Fig. 7a). When human satellite cell-derived myogenic precursors were similarly injected into the femoral artery of scid- $m d x$ mice, no signal (over background) could be detected in downstream muscles (data not shown), confirming our previous results in mice 9

One week after injection, many human nuclei were identified (by the anti-human lamin $\mathrm{A} / \mathrm{C}$ antibody), mainly outside the basal lamina. A fraction (approximately 15\%) of injected cells was actively proliferating $\left(\mathrm{Ki}^{+} \mathrm{7}^{+}\right.$- as shown in Fig. 7b, where human nuclei are indicated in red and proliferating human cells (arrows) in yellow in the merged image. Many human cells expressed NG2 (Fig. 7c-e); however, several human 

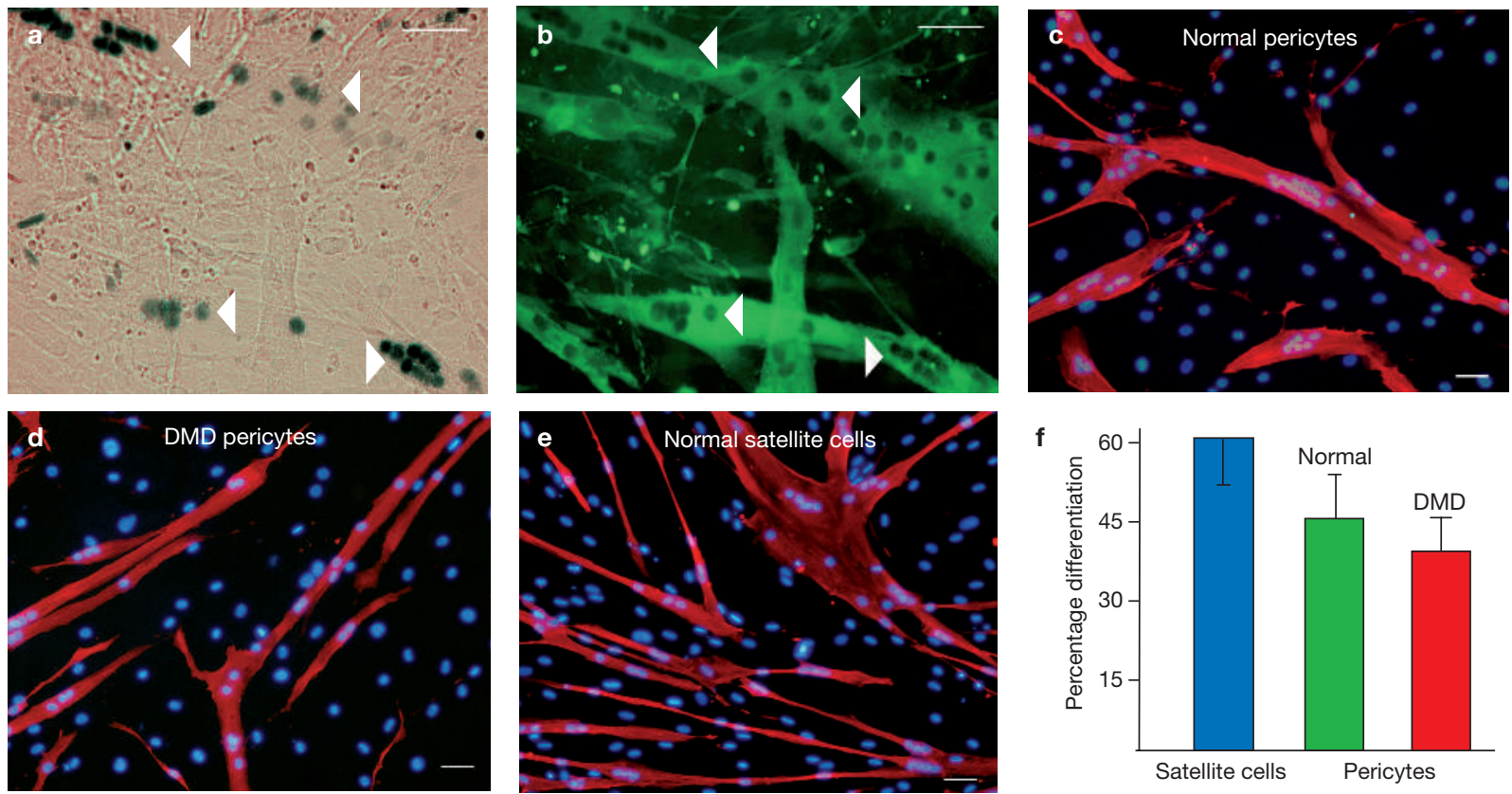

g

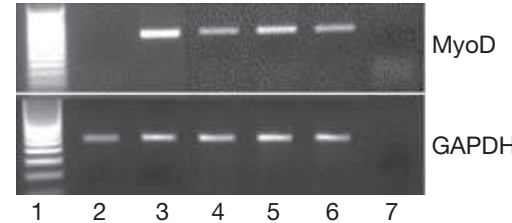

h

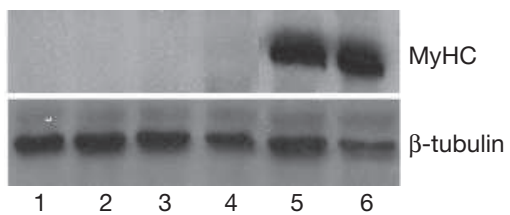

Figure 5 In vitro myogenic differentiation of human pericyte derived cells. (a, b) Fusion of pericyte-derived human cells, previously transduced with a lentiviral vector expressing nuclear LacZ after coculture with mouse C2C12 myoblasts. Human LacZ+ ${ }^{+}$nuclei (arrowheads) are mainly detected inside multinucleated, myosin positive myotubes. (c-f) Spontaneous differentiation of normal (c) and dystrophic (d) human pericyte-derived cells, cultured in differentiation medium on matrigel coated dishes. Normal human satellite cell-derived myotubes are shown in e for comparison. A quantitative analysis of the percentage of differentiation is shown in $\mathbf{f}$. (g) RT-PCR with human specific oligonucleotides for human MyoD expression in the coculture shown in $\mathbf{a}$ and $\mathbf{b}$. Lane 1, molecular markers; lane 2, C2C12 mouse myoblasts; lane 3, human satellite cells; lanes 4-6, cocultures of C2C12 myoblasts with different isolates of human pericyte-derived adult cells; lane 7, no DNA. (h) Western blot analysis for the expression of sarcomeric myosin heavy chains (MyHC) in normal (lanes 1, 3 and 5) and DMD (lanes 2, 4 and 6) pericyte-derived human cells cultured in growth medium (lane 1,2 ) and in differentiation medium for one (lanes 3, 4) and eight (lanes 5, 6) days. The scale bars represent $50 \mu \mathrm{m}$ in $\mathbf{a}$ and $\mathbf{b}$ and $25 \mu \mathrm{m}$ in $\mathbf{c}-\mathbf{e}$. nuclei (approximately 3-5\% of total human nuclei) could be detected underneath the basal lamina expressing M-Cadherin, a specific marker of satellite cells (Fig. 7f-h).

To examine the residual clonogenicity of transplanted ALP+ ${ }^{+} \mathrm{CD}_{56}{ }^{-}$ cells, muscles from $s c i d-m d x$ mice were digested one week after injection. Four percent of freshly dissociated cells were of human origin and $90 \%$ of these were $\mathrm{ALP}^{+}$, whereas no human cell was $\mathrm{Myf5}^{+}$. When dissociated cells were cultured for three days and then stained for lamin A/C and Myf5, several cells expressing either one or the other antigen could be detected (see Supplementary Information, Fig. 2a-c), but none expressing both markers. This indicates that human satellite cells (identified by coexpression of Myf5 and M-Cadherin; see Supplementary Information, Fig. 2d) were not present in the transplanted population. These cells were cloned by limiting dilution and 45 clones were obtained (cloning efficiency, approximately $2 \%$ ): two were $\mathrm{Myf5}^{+}$(see Supplementary Information, Fig. 2e-g); 41 were $\mathrm{ALP}^{+}$(see Supplementary Inforamtion, Fig. 2h, j); and two were negative for both markers (data not shown). A polyclonal culture with $\mathrm{ALP}^{+}$human cells and $\mathrm{ALP}^{-}$mouse cells is shown in the Supplementary Information, Fig. $2 \mathrm{k}$. When expansion of rescued human clones was attempted, three out of 20 clones were propagated for approximately 10 population doublings, indicating that only a minority of the transplanted population maintains a high proliferative capacity in vivo (data not shown).

\section{Dystrophin production by transplanted cells}

We finally examined whether transplanted cells would fuse into multinucleated myofibres that expressed human dystrophin, one month after the last of three intra-arterial transplantations into scid- $m d x$ mice. Specific staining of anti-Dys1, Dys2 and human-specific Dys3 antibodies was determined by staining a section of a transplanted tibialis anterior only with secondary antibody, which did not produce any staining (Fig. 8a, $a^{\prime}$ ) using our conditions (see Methods). When non-transplanted tibialis anterior of 2-month-old scid-mdx mice was stained with anti-Dys1 or Dys2 antibodies, several clusters of revertant fibres (ranging in number between 5 and 15), were observed (see Fig. 8b, b'). After three consecutive injections ${ }^{9}$ of normal pericyte-derived cells, large areas of the injected muscle were reconstituted with fibres expressing human dystrophin (Fig. 8c, $\mathrm{c}^{\prime}$ and Table 1). The number of dystrophin positive fibres in the tibialis anterior of transplanted animals (stained with anti-Dys3 antibody) ranged between 200 and 450 in five different transplanted 

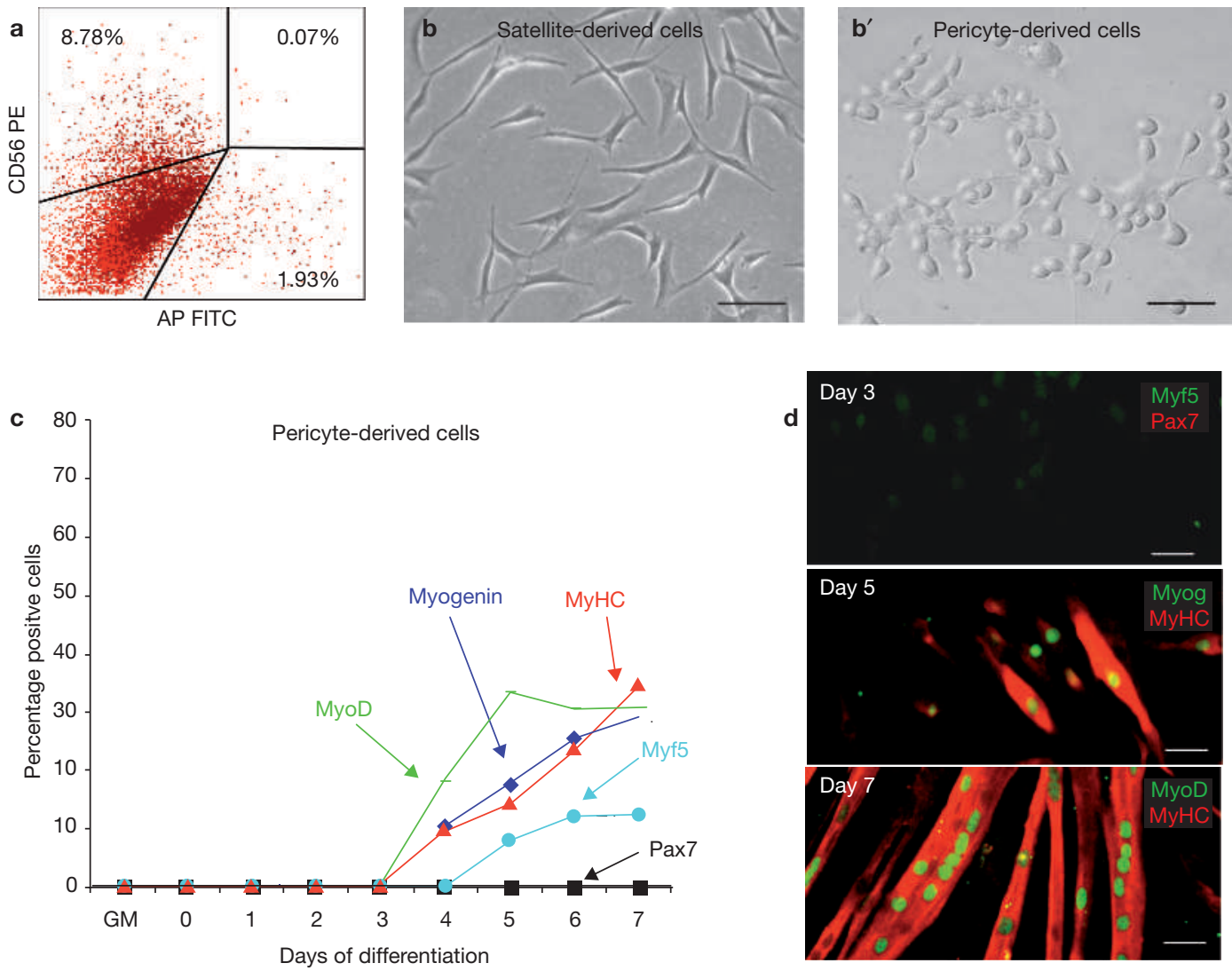

e

Satellite-derived myogenic cells

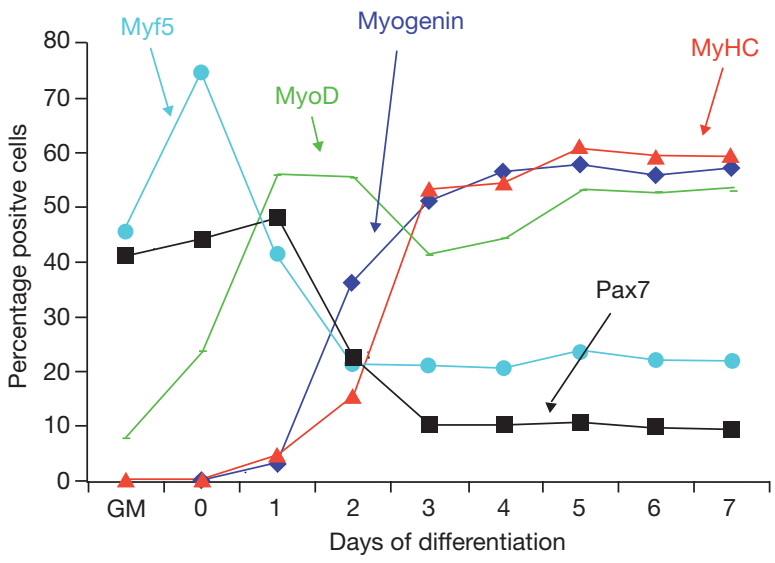

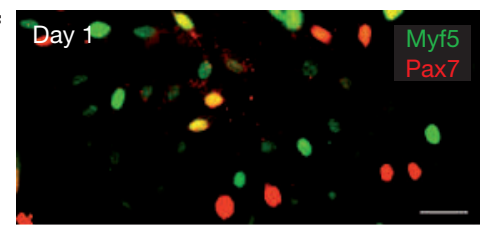
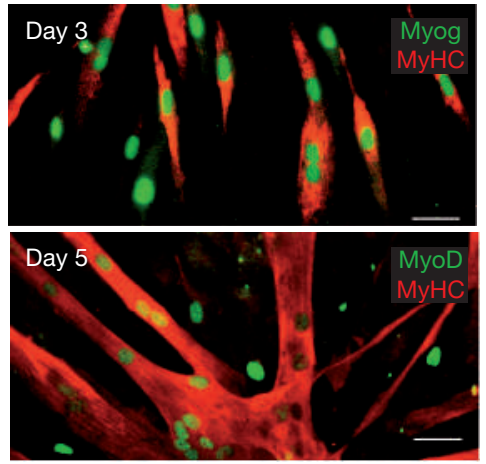

Figure 6 Time course of myogenic differentiation in cultures of pericyte-derived cells and satellite cell-derived myogenic precursors. (a) Cells were digested from human skeletal muscle and FACS sorted into $\mathrm{CD} 56^{+}$satellite cells and $\mathrm{ALP}^{+}$pericytes, which were separately cultured in myogenic-promoting conditions. (b, $\mathbf{b}^{\prime}$ ) Phase-contrast morphology of the two cell types at day 1 in culture are shown in $\mathbf{b}$ and $\mathbf{b}^{\prime}$, respectively. (c-f) Positive cells were counted

mice. When human dystrophic cells, transduced in vitro with a lentiviral vector expressing human mini-dystrophin, were similarly injected into the skeletal muscle of $s c i d-m d x$ mice, the results were similar to those observed with normal cells (Fig. 8d, d'), with numbers of minidystrophin-postive fibres ranging from 190 to 320 per crosssectional area. In one experiment, three mice were transplanted intra-arterially in 20 randomly selected fields and calculated as percentage of total nuclei visualized by DAPI. The time-course of expression of these different proteins are shown for pericyte derived cells (c) and for satellite cells (e). Cultures were fixed and stained daily with antibodies against Pax7, Myf5, MyoD, myogenin and myosin heavy chains - examples are shown in $\mathbf{d}$ for pericyte-derived cells and in $\mathbf{f}$ for satellite cells. The scale bars represent $20 \mu \mathrm{m}$.

with a clonal population of $\mathrm{ALP}^{+}$pericyte-derived cells using the same protocol as for polyclonal population. The number of dystrophin-positive fibres detected was similar to that observed with the polyclonal population (Table 1). To compare the myogenic potential of pericytederived cells with satellite cells, scid- $m d x$ mice were transplanted with three consecutive intra-arterial injections of human $\mathrm{CD}^{2} 6^{+}$satellite cells. 

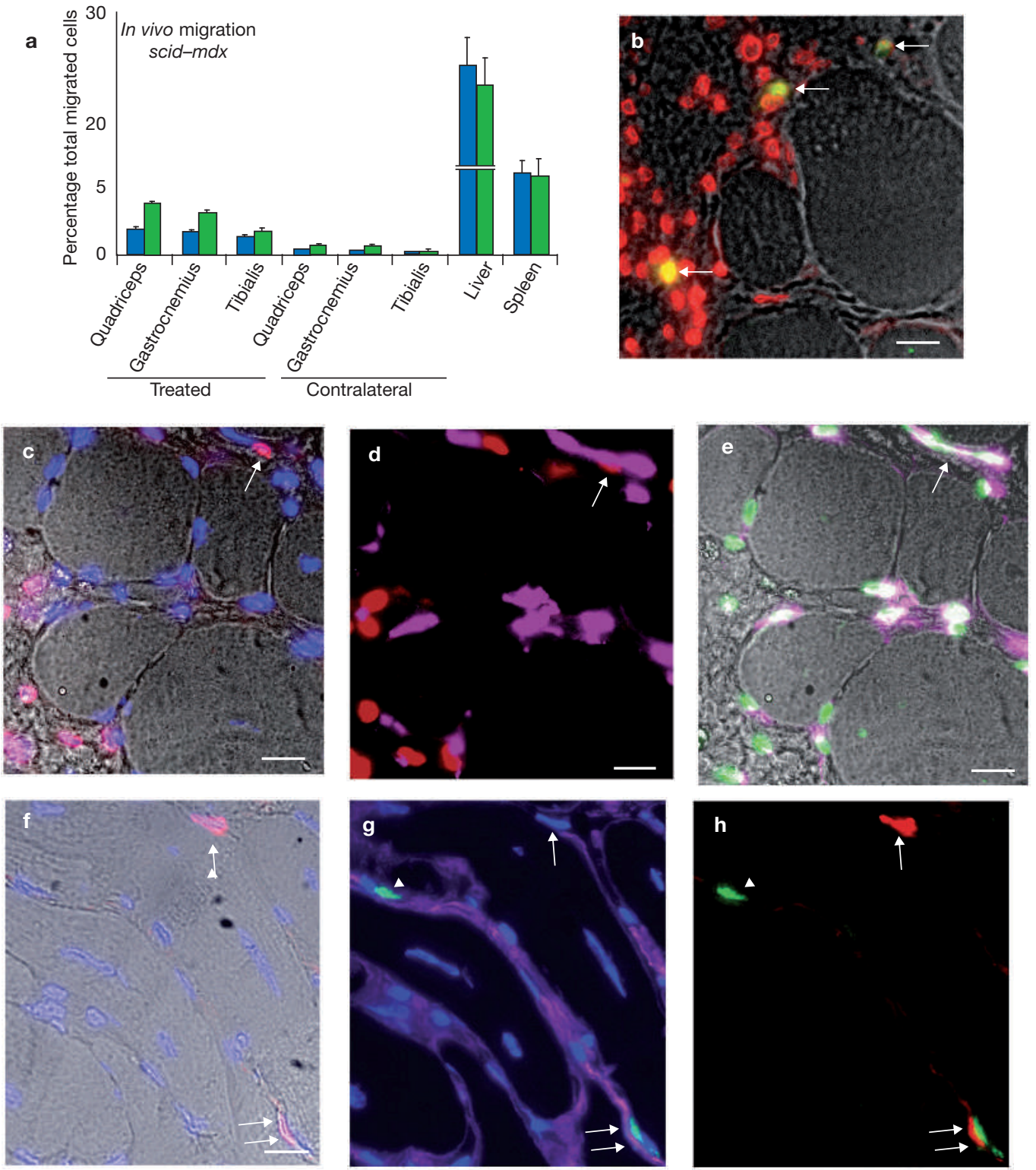

Figure 7 Tissue distribution of human pericyte-derived cells in dystrophic muscle. (a) In vivo homing of $5 \times 10^{5}$ mouse male mesoangioblasts (blue bars) or human (green bars) male pericyte-derived cells, injected into the right femoral artery (treated muscles) of 2-month-old female scid-mdx mice. After $24 \mathrm{~h}$, different organs were collected and the percentage of migrated cells was calculated by real-time PCR for the Y chromosome. A mean of three independent experiments run in triplicate is shown. The error bars represent s.d. (b) High magnification of human cells 7 days after transplantation in the mouse muscle. Human lamin A/C-positive cells are visible in red and the fraction of these cells that are proliferating are visible in yellow in the merged image of the section (also stained with anti-Ki67 antibody). The fluorescence image is superimposed on the phase-contrast image of the tissue. (c-e) Triple-fluorescence images of transplanted human cells

The number of dystrophin positive fibres detected in these animal was very low (Table 1), and is likely to represent revertant fibres. These data confirm that satellite cells cannot colonize muscle when systemically delivered. For a more direct comparison, both pericyte-derived cells and satellite cells were transplanted with a single intra-muscular injection into the tibialis anterior $s c i d-m d x$ mice. In this case, both populations coexpressing pericyte markers. Human nuclei stained with anti-lamin $\mathrm{A} / \mathrm{C}$ and DAPI appear violet (arrow), whereas mouse nuclei appear blue (c). Human nuclei stained with anti-Lamin A/C (red) also express NG2 (magenta, d). NG2expressing pericytes (magenta) adjacent to CD31 expressing, endothelial cells (green, e). (f-h) Human pericyte-derived cells localize underneath the basal lamina and express the satellite cell marker M-Cadherin. Human nuclei are stained with anti Lamin $A / C$ antibody (arrows in $\mathbf{f}$ and $\mathbf{h}$ ) and appear violet in $\mathbf{f}$ (because of DAPI counterstain) and red in $\mathbf{h}$. Satellite cells are stained in green by an M-Cadherin antibody ( $\mathbf{g}$ and $\mathbf{h}$ ). The double arrow indicates a human cell, expressing M-Cadherin, underneath the basal lamina that is stained magenta by anti-laminin antibody $(\mathbf{g})$, whereas the arrowhead indicates a mouse satellite cell $(\mathbf{g}, \mathbf{h})$. Nuclei are counter-stained in blue with DAPI (f, g). The scale bars represent $20 \mu \mathrm{m}$ in all panels.

of cells gave rise to numerous dystrophin-positive fibres in the area of injection, with satellite cells being more efficient than pericyte-derived cells (Table 1). Finally, ALP--CD56- fibroblasts did not give rise to significant numbers of dystrophin-positive cells, independent from the route of administration (Table 1). The amount of human dystrophin expressed in muscles transplanted intra-arterially with pericyte-derived 
Table 1 Human cell types injected into irradiated scid-mdx host mice

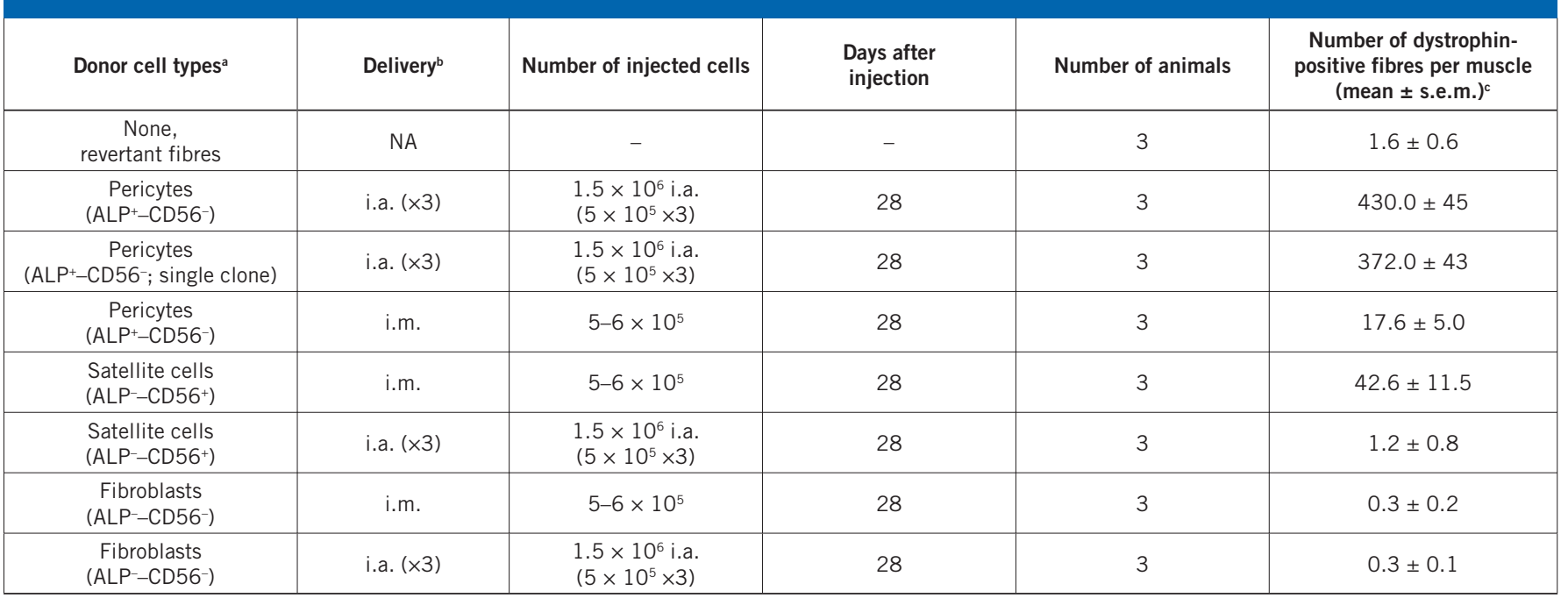

${ }^{a}$ Cells were injected at between 10 and 20 population doublings, whereas clones were injected at 25 population doublings. ${ }^{\circ} N A$, not available; i.m., single intra-muscular injection into tibialis anterior; i.a., three consecutive intra-femoral artery injections. cIn all injectedanimals, only the tibialis anterior was analysed.

cells was analysed by western blot (Fig. $8 \mathrm{~g}$ ), which revealed significant accumulation of both normal and mini-dystrophin in the transplanted quadriceps, although there were differences between different transplanted animals.

\section{Functional analysis}

SCID $(n=4)$, SCID-mdx-untreated mice $(n=3)$ and SCID-mdx mice ( $n=7$ ), transplanted with human pericyte-derived cells (normal, $n=4$; DMD genetically corrected, $n=3$ ), were tested for functional recovery on a rotarod at a fixed speed of $1.6 \mathrm{~m} \mathrm{~min}^{-1}$ up to $4 \mathrm{~min}$. Results (see Supplementary Information, Fig. S3a) showed that SCID mice fell in only three times (after 320, 335 and 340 s) out of 12 tests, whereas untreated SCID-mdx fell at all times, after running periods ranging from 30 to $160 \mathrm{~s}$ (nine out of nine). SCID-mdx mice, transplanted with normal human pericyte-derived cells, fell 10 out of 12 times, and in two cases completed the test (in the other cases they fell after periods ranging from 70-300 s). SCID-mdx mice, transplanted with DMD pericyte-derived cells and transduced with the lenti-vector expressing human mini-dystrophin, fell seven out of nine times, after periods ranging between 60 and $310 \mathrm{~s}$. Transplanted mice were also subjected to the exhaustion treadmill, which measures muscle endurance - untreated SCID-mdx mice showed a lower time of exhaustion in the this test compared with SCID mice (see Supplementary Information, Fig. 3b). The groups receiving donor human pericyte-derived cells performed significantly better than untreated dystrophic mice at all times, even though they did not reach the level of activity of normal mice. These data showed a partial, but significant, recovery of motility in mice transplanted with human pericyte-derived cells.

\section{DISCUSSION}

This work describes the isolation of cells that can proliferate in vitro from interstitial tissues of normal and dystrophic human skeletal muscle. The cells can be expanded in vitro for about 20 population doublings (up to numbers that would be sufficient to treat a paediatric patient), transduced with viral vectors and induced to differentiate into skeletal muscle. When transplanted into dystrophic immunodeficient mice, they gave rise to large numbers of new fibres expressing human dystrophin, thus fulfilling all the criteria required for a successful cell therapy for muscular dystrophy.

Unexpectedly, we observed that cells outgrown from tissue explants express ALP and a number of pericyte markers, and can be isolated from pericytes - the only $\mathrm{ALP}^{+}$cells in skeletal muscle ${ }^{11}$. At variance with embryonic mesoangioblasts, they do not express endothelial markers. A possible interpretation of this difference may be found in the angioblastic origin of mesoangioblasts ${ }^{14}$, which occupy an endothelial position in the embryo and express some early endothelial markers. With further development, these cells may move to a perithelial position, progressively switching from an 'endothelium-like' to a 'pericyte-like' phenotype, similar to the phenotype observed in this work. Although it is possible that the cells we isolated and characterized from pericytes may be the progeny of prenatal mesoangioblasts, the lineage relationship may be complex and cannot be determined in humans, where genetic labelling is not feasible. Operationally, we define these cells as 'pericyte-derived cells'

Myogenic differentiation of pericyte-derived cells is strikingly high, ranging from 20 to $40 \%$ in cells from different patients. This is approximately one order of magnitude more than that observed for other types of stem cells, including mouse mesoangioblasts ${ }^{8,9}$. However, these cells are clearly distinct from satellite cells as they have a number of unequivocal characteristics: first, they have a different anatomical niche - pericytes are located underneath the basal lamina of the small vessel, whereas satellite cells are located inside the basal lamina of muscle fibres; second, their growth requirements differ, as pericyte-derived cells undergo rapid senescence in DMEM which is routinely to culture satellite cells; third, satellite cells express MyoD, Pax7, Myf5, MEF 2C, CD56 and $\mathrm{M}$-cadherin, which are not expressed in pericyte-derived cells that instead express NG2 and ALP (not expressed in satellite cells). Interestingly, pericyte-derived cells express MyoD and Myf5 only on terminal differentiation, suggesting distinct kinetics of myogenic differentiation. Moreover, pericyte-derived cells can cross the vessel wall - a feature presumed to be absent in satellite cell-derived myogenic precursors. In 1992, it was reported that myogenic cells can be delivered arterially ${ }^{15}$, but this crucial experiment was never repeated despite 

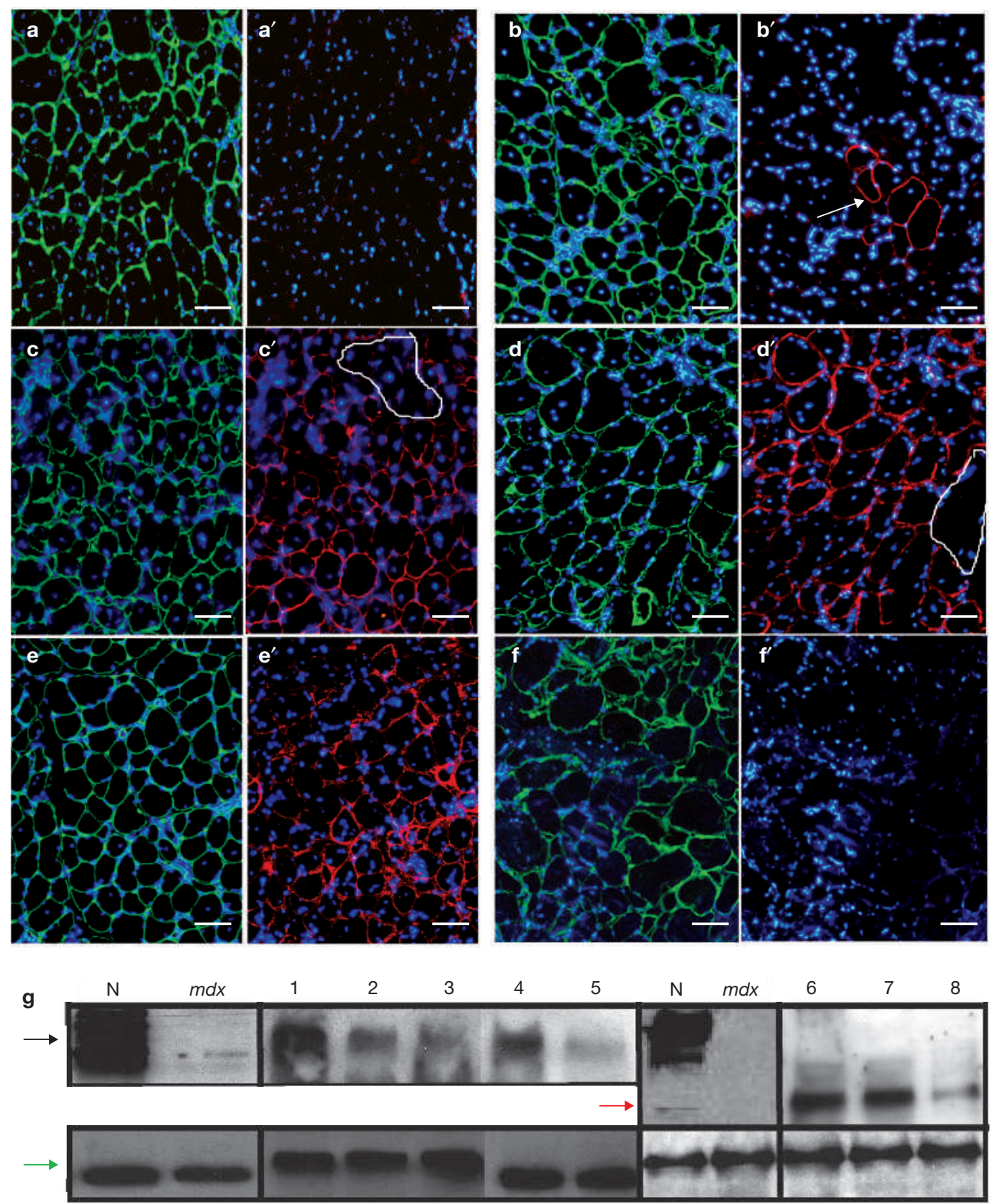

Figure 8 Immunofluorescence microscopy and western blot analysis of $s c i d-m d x$ mouse tibialis anterior, after three serial transplantations of $5 \times 10^{5}$ human normal pericyte-derived cells and stained with antibodies against laminin (green) and human dystrophin (Dys1/Dys2 or Dys3, red). (a, a') Section stained with secondary antibody only. (b, $\left.\mathbf{b}^{\prime}\right)$ Immunofluorescence microscopy analysis of non-transplanted $s c i d-m d x$ mouse tibialis anterior stained with anti-Dys 1 and Dys2 antibodies. A cluster of revertant fibres is clearly evident (arrow). (c, $\mathbf{c}^{\prime}$ ) Section of $s c i d-m d x$ mouse tibialis anterior, after three serial transplantation of $5 \times 10^{5}$ human normal pericyte-derived cells. Many dystrophin-positive fibres are present throughout the section and a dystrophin-negative area is indicated by the white line. (d, $\mathbf{d}^{\prime}$ ) Section of $s c i d-m d x$ mouse tibialis anterior, after three serial transplantations of $5 \times 10^{5}$ human DMD pericyte-derived cells (in vitro transduced with a lentiviral vector expressing human mini-dystrophin) after staining with antibodies against

the obvious importance of systemic delivery. We found that arterially delivered satellite cell-derived myogenic precursors were found inside the vessels, but not outside of them ${ }^{\text {. }}$.

A detailed comparison of human adult pericyte-derived cells with mesenchymal stem cells (MSCs) ${ }^{16}$, that will be reported elsewhere, laminin (green) and human dystrophin. Many mini-dystrophin positive fibres are present throughout the section and a negative area is indicated by dashed line. (e, $\mathbf{e}^{\prime}$ ) Section of $s c i d-m d x$ mouse tibialis anterior, after intra-muscular injection of $5 \times 10^{5}$ human satellite cells. Many dystrophin-positive fibres are present in the area of injection. ( $\left.\mathbf{f}, \mathbf{f}^{\prime}\right)$ Section of $s c i d-m d x$ mouse tibialis anterior, after intra-muscular injection of $5 \times 10^{5}$ human fibroblasts. No dystrophin-positive fibres were detected. (g) Western blot analysis of human dystrophin expressed in muscles from different mice transplanted with $5 \times 10^{5}$ human normal pericyte-derived cells (lanes $1-5$ ) and with DMD human pericyte-derived cells, transduced with a lentiviral vector expressing human mini-dystrophin, (lanes 6-8). Normal and DMD skeletal muscle are shown as controls. The black arrow indicates wild-type dystrophin, the red arrow indicates mini-dystrophin and the green arrow indicates myosin heavy chains, shown as loading control. The scale bars represent $100 \mu \mathrm{m}$ in a-f'.

showed that the two cell populations clearly differ in the expression of a significant number of genes. Moreover, human pericyte-derived cells do not grow in a-MEM, the medium used for MSCs. Finally, MSCs cannot differentiate into skeletal muscle spontaneously and do so at low frequency only after treatment with $5^{\prime}$-N-cytidine ${ }^{17}$. 
In the past few years, many different types of mesodermal stem cells have been isolated from both mouse and human tissues, and characterized to different extents. These include: endothelial precursor cells $(\mathrm{EPCs})^{18}$; multipotent adult precursor cells $(\mathrm{MAPCs})^{19}$; muscle derived stem cells (MDCSs) ${ }^{20}$; side population cells ${ }^{21-23}$; Ac133 ${ }^{+}$cells $^{24}$; mesoangioblasts $^{8}$; and stem and/or precursor cells from muscle endothelium ${ }^{25}$, sinovium $^{26}$, dermis ${ }^{27}$, and adipose tissue ${ }^{28}$. Different experimental procedures, different sources and partial characterization still prevent a complete understanding of the heterogeneity of these cells, and even less is known of their origin and possible lineage relationships. Whatever the case, many of these cells have been shown to differentiate into skeletal muscle in vitro (MDSCs have also been shown to differentiate in vivo). Some of these cells grow extensively in vitro, but others (such as EPCs and side population cells) do not. Furthermore, EPCs and side population cells can circulate, whereas systemic delivery has not been examined for most of the other cell types. Currently, human pericyte-derived cells are the only cell type for which all the requested criteria have been validated, although it is possible that other mesodermal stem cells may show similar features - for example, cells isolated from adipose tissue give rise to a few human dystrophin-expressing fibres when injected into mdx mice ${ }^{28}$. Also, MSCs transduced with the intracellular active domain of Notch and exposed to certain cytokines give rise to numerous fibres in vitro and in the mdx muscle ${ }^{29}$. This result is intriguing, but awaits a molecular explanation of the paradoxical effect of Notch, a known inhibitor of myogenesis ${ }^{30}$ that also has transforming ability ${ }^{31}$.

In future clinical protocols, systemic delivery seems to be an obligate choice, as intra-muscular delivery would require an excessive number of injections. Pericyte-derived human cells express some of the proteins that leukocytes use to adhere to and cross the endothelium (that is, $\beta 2$ and $a 4$ integrins), and thus can diffuse into the interstitium of skeletal muscle when delivered intra-arterially (a distinct advantage over resident satellite cells that cannot).

Moreover, their extensive, but not indefinite, in vitro proliferation and the maintenance of normal karyotype and myogenic potency, indicates that human adult pericytes from a single biopsy may generate enough cells to treat a paediatric patient with minimal risk of malignant transformation. Importantly, dystrophic cells show the same proliferation ability of their normal counterparts, suggesting that the disease has not exhausted their growth potency, at least at a young age.

In conclusion, we have shown that pericytes represent a second myogenic precursor, resident in adult human skeletal muscle, with similar myogenic potency to, but phenotypically distinct from, satellite cells. Because of these features, pericyte-derived cells are an ideal cell population for future cell therapy of muscular dystrophy.

\section{METHODS}

Isolation and culture of human adult pericyte-derived cells. Cells were prepared from ten patients undergoing diagnostic biopsy and later classified as non-dystrophic (and non affected by secondary myopathies) and from six DMD patients, ranging in age from 15-78 years (non DMD) and 3-8 years (DMD). The muscle samples (100-200 mg) from needle biopsies of the biceps brachialis were stored in DMEM w/o FCS, with antibiotics and kept at $4{ }^{\circ} \mathrm{C}$ for maximum $24 \mathrm{~h}$ before dissection. The muscle samples were rinsed in PBS with $\mathrm{Ca}^{2+}-\mathrm{Mg}^{2+}$ and sharply dissected into 1-2 mm diameter pieces with a scalpel. Fragments of interstitial tissues containing small vessels were transferred to a Petri dish coated with type I collagen ( $1 \mathrm{mg} \mathrm{ml}^{-1}$ in $0.1 \mathrm{M}$ acetic acid). The medium consisted of MegaCell DMEM (Sigma, St Louis, MO) supplemented with 5\% FCS, $5 \mathrm{ng} \mathrm{ml}^{-1}$ basic fibroblast growth factor, $2 \mathrm{mM}$ glutamine, $0.1 \mathrm{mM} \beta$-mercaptoethanol, $1 \%$ non essential aminoacids, $100 \mathrm{IU} \mathrm{ml}^{-1}$ penicillin and $100 \mathrm{mg} \mathrm{ml}^{-1}$ streptomycin. The tissue fragments were cultured for $7-8$ days. After the initial outgrowth of fibroblast-like cells, small round and refractile cells were observed (Fig. 1a). Because of their poor adhesion (many of these cells were floating), this cell population was easily collected by gently pipetting of the original culture and was plated on collagen-coated dishes at a density of $5 \times 10^{4}$ cells per $30-\mathrm{mm}$ dish. The cells were either grown as a polyclonal population or cloned by limiting dilution on collagen-coated dishes.

Satellite cell and fibroblast cultures. Satellite cells were isolated from biopsies of human skeletal muscle, as routinely performed in our laboratory ${ }^{32}$ (see Supplementary Information, Methods).

Cell cloning. Cells isolated from either explants or enzymatic digestion were stained with Trypan blue, and living cells (excluding the dye) were counted in a haemocytometer. The cell suspension was cloned by limiting dilution in the same medium used for mass culture.

Flow cytometry and sorting. Cells were isolated from normal and DMD muscle and analysed by flow cytometry or separated through a fluorescence activated cell sorter (see Supplementary Information, Methods).

Analysis of cell proliferation. Cells were plated at a density of $5 \times 10^{3}$ cells per $\mathrm{cm}^{2}$ in different media, and passed on average every three days. At each passage, the number of cells was counted in triplicate in a haemocytometer.

Karyotype analysis. All cell isolates from each individual patient were karyotyped at an early and at a late passage. Cells, plated at one third confluence $72 \mathrm{~h}$ before analysis, were processed with the Karyomax kit (Invitrogen, Paisley, UK) according to the manufacturer's instructions. For each of the karyotypes analysed, five different metaphase spreads were examined.

Telomerase activity and telomere-length analysis. Telomerase activity was determined in three different samples using the TRAP assay, as described previously $^{33}$. Telomere length was measured after DNA extraction from cell samples with different population doublings by digestion with the restriction enzymes AluI, CfoI, HaeIII, Hinfl, MspI and RsaI, and electrophoresis on $0.7 \%$ agarose gels as previously described ${ }^{34}$. The gels were denatured, dried and neutralized, and the signal was detected in situ using a telomeric probe end-labelled with ${ }^{32} \mathrm{P}$-ATP.

Tumorigenicity. To test for possible tumour formation, 10 nude and 10 SCID mice were injected subcutaneously each with $1 \times 10^{7}$ human pericyte-derived cells from two non-DMD (age 15, 40) patients (five nude and five SCID each), and maintained for one year after the injection. The same number of mice were similarly each injected with $1 \times 10^{7}$ pericyte-derived cells from two DMD patients (age 3 and 6), previously transduced with a lentiviral vector expressing human mini-dystrophin. After 12 months, the mice were killed and analysed for the presence of macroscopically detectable tumours.

Cell transduction with lentiviral vectors. Cells were transduced, as previously described $^{9}$, with third-generation lentiviral vectors expressing nuclear LacZ or human mini-dystrophin ${ }^{35}$.

Differentiation assays. Differentiation into smooth muscle cells and osteoblasts was induced by treatment with TGF $\beta-1$ and BMP2, respectively, as previously described ${ }^{8}$. Differentiation into skeletal muscle cells was induced by coculturing human adult pericyte-derived cells (previously transduced with a lentivector expressing n-LacZ) with C2C12 mouse myoblasts at 1:5 ratio (see Supplementary Information, Methods).

Spontaneous skeletal myogenic differentiation of human pericyte-derived cells was induced by plating cells onto matrigel-coated dishes in differentiation medium. After 7 days, cultures were fixed and stained with antibodies against striated myosin (MF20) and MyoD. Western blot analysis was performed using the same antibodies. Human satellite cells, used as a positive control, were cultured as previously described ${ }^{32}$.

Immunofluorescence microscopy. Cells were grown on matrigel-coated glass coverslips for 2 days at an initial concentration of $2 \times 10^{4}$ per coverslip), washed with PBS and fixed with $4 \%$ paraformaldehyde for $10 \mathrm{~min}$. Muscle samples from 
control, or cell-transplanted scid- $m d x$ mice were frozen in liquid nitrogen-cooled isopentane and serial $8 \mu \mathrm{m}$-thick sections were cut with a Leyca cryostat. Cells and tissue sections were processed for immunofluorescence microscopy as previously described $^{8}$ (see Supplementary Information, Methods).

Immunoblotting and antibodies. Western blotting analysis of cells and tissues was performed as previously described ${ }^{8,9}$. The antibodies used in this study are described in the Supplementary Information, Methods.

In vivo transplantation. Approximately $5 \times 10^{5}$ human pericyte-derived cells and mouse D16 mesoangioblasts (both male) were injected into two-month-old female scid-mdx dystrophic mice, as previously described ${ }^{9}$. Animals were killed at different times after the injection. To measure the fraction of injected cells retained into skeletal muscles, animals were sacrificed $24 \mathrm{~h}$ after the injection, and different muscles (quadriceps, gastrocnemius and tibialis anterior) or filter organs (liver, lung and spleen) were collected. RNA was extracted and a real-time PCR for the Y chromosome was performed in all the samples, as described elsewhere. Data are represented as percentage of cells (percentage of $Y$ chromosome detected) migrated to the different organs relative to the input value. To analyse human dystrophin expression, three consecutive injections at 30 day intervals were performed, and animals were sacrificed 20 days after the last injections. The injected and non-injected tibialis anterior were processed for immunofluorescence microscopy, whereas a membrane fraction was purified from the injected quadriceps of the same mice, separated of 6\% SDS-PAGE and analysed by western blot, as previously described ${ }^{8}$. Human satellite cells and fibroblasts were injected intra-arterially following the same protocol.

Alternatively, $5 \times 10^{5}$ pericyte-derived cells $\left(\mathrm{ALP}^{+}-\mathrm{CD}^{-} 6^{-}\right)$, satellite cells $\left(\mathrm{ALP}^{-}-\mathrm{CD} 56^{+}\right)$or fibroblasts $\left(\mathrm{ALP}^{-}-\mathrm{CD}^{-} 6^{-}\right)$were suspended in $10 \mu \mathrm{lBS}$ and injected intra-muscularly in the tibialis anterior of scid-mdx mice, as previously described ${ }^{32}$.

Gene-expression profiling and data analysis. Gene expression profiling analysis was conducted on total cellular RNA isolated from different cell populations: two DMD patients, age 3 and 6; two healthy individuals, age 15 and 40; and from two clones of the 40 years old individual (see Supplementary Information, Methods).

Exercise protocols. Control, dystrophic, and dystrophic transplanted mice were subjected to functional analysis using a rotarod and treadmill (see Supplementary Information, Methods).

Note: Supplementary Information is available on the Nature Cell Biology website.

\section{ACKNOWLEDGEMENTS}

This work was supported by grants from Muscular Dystrophy Association (MDA), Telethon, Association Française contra les Myopathies (AFM), Parent Project Onlus, Cassadi Risparmio Province Lombarde (CARIPLO), Associazione Italiana ricerca sul Cancro (AIRC), EC 'Eurostemcell', 'Cellsintoorgan', MyoAmp and 'Genostem', and the Italian Ministries of Health and Research. We thank G. Arrigo for help with karyotype analysis and A. Palini for help with FACS analysis. We also thank E. Dejana for advice and for reading the manuscript.

\section{AUTHOR CONTRIBUTIONS}

A.D. and M.S. coordinated the work and performed the in vivo transplantation and functional tests. R.T. performed the cell cultures with help from G.M. and R.M. E.T. and S.F. conducted the microarray analysis. B.S. and A.D. did the FACS work. L.P. performed the PCR and western blot analysis. A.I. and M.B. did the immunocytochemistry. B.G.G. performed the homing experiment. S.L. and J.S.C. provided the viral vectors and advice. G.P. and Y.T. provided the biological samples. W.E.W. performed the telomerase work, provide advice and revised the manuscript. P.B. and G.C. coordinated the whole project and wrote the manuscript.

\section{COMPETING FINANCIAL INTERESTS}

The authors declare that they have no competing financial interests.

Published online at http://www.nature.com/naturecellbiology/

Reprints and permissions information is available online at http://npg.nature.com/ reprintsandpermissions/

1. Mauro, A. Satellite cell of skeletal muscle fibers. J. Biophys. Biochem. Cytol. 9, 493495 (1961).

2. Sherwood, R. I. et al. Isolation of adult mouse myogenic precursors: functional heterogeneity of cells within and engrafting skeletal muscle. Cell 119, 543-554 (2004).
3. Collins, C. A. et al. Stem cell function, self-renewal, and behavioral heterogeneity of cells from the adult muscle satellite cell niche. Cell 122, 289-301 (2005).

4. Morgan, J. E. et al. Long-term persistence and migration of myogenic cells injected into pre-irradiated muscles of mdx mice. J. Neurol. Sci. 115, 191-200 (1993).

5. Beauchamp, J. R., Morgan, J. E., Pagel, C. N. \& Partridge, T. A. Dynamics of myoblast transplantation reveal a discrete minority of precursors with stem cell-like properties as the myogenic source. J. Cell Biol. 144, 1113-1121 (1999).

6. Montarras, D. et al. Direct isolation of satellite cells for skeletal muscle regeneration. Science 309, 2064-2067 (2005).

7. Cossu, G. \& Sampaolesi, M. New therapies for muscular dystrophy: cautious optimism? Trends Mol. Med. 10, 516-520 (2004).

8. Minasi, M. G. et al. The meso-angioblast: a multipotent, self-renewing cell that originates from the dorsal aorta and differentiates into most mesodermal tissues. Development 129, 2773-2783 (2002).

9. Sampaolesi, M. et al. Cell therapy of a sarcoglycan null dystrophic mice through intraarterial delivery of mesoangioblasts. Science 301, 487-492 (2003).

10. Armulik, A., Abramsson, A. \& Betsholtz, C. Endothelial/pericyte interaction. Circ. Res. 97, 512-523 (2005).

11. Safadi, A., Livne, E., Silbermann, M. \& Reznick, A. Z. Activity of alkaline phosphatase in rat skeletal muscle localized along the sarcolemma and endothelial cell membranes. J. Histochem. Cytochem. 39, 199-203 (1991).

12. Katagiri, T. et al. Bone morphogenetic protein-2 converts the differentiation pathway of C2C12 myoblasts into the osteoblast lineage. J. Cell Biol. 127, 1756-1766 (1994).

13. Galvez, B. G. et al. Complete repair of dystrophic skeletal muscle by mesoangioblasts with enhanced homing ability. J. Cell Biol. 174, 231-243 (2006).

14. Cossu, G. \& Bianco, P. Mesoangioblasts, vascular precursors for extra-vascular mesoderm. Curr. Opin. Genet. Develop. 13, 537-542 (2003).

15. Neumeyer, A. M. et al. Arterial delivery of myoblasts to skeletal muscle Neurology 42 , 2258-2262 (1992)

16. Bianco, P. \& Gehron Robey, P. Marrow stromal stem cells. J. Clin. Invest. 105, 16631668 (2000).

17. Wakitani, S., Saito, T. \& Caplan, A. I. Myogenic cells derived from rat bone marrow mesenchymal stem cells exposed to 5-azacytidine. Muscle Nerve 12, 1417-1426 (1995).

18. Asahara, T. et al. Isolation of putative precursor endothelial cells for angiogenesis Science 275, 964-967(1997).

19. Reyes, M. et al. Purification and ex vivo expansion of postnatal human marrow mesodermal precursor cells. Blood 98, 2615-2625 (2001).

20. Qu-Petersen, Z. et al. Identification of a novel population of muscle stem cells in mice: potential for muscle regeneration J. Cell Biol. 157, 851-864 (2002).

21. Asakura, A., Seale, P., Girgis-Gabardo, A. \& Rudnicki, M. A. Myogenic specification of side population cells in skeletal muscle. J. Cell Biol. 159, 123-134 (2002).

22. LaBarge, M. A. \& Blau, H. M. Biological progression from adult bone marrow to mononucleate muscle stem cell to multinucleate muscle fiber in response to injury. Ce// 111, 589-601 (2002)

23. Bachrach, E. et al. Systemic delivery of human mini-dystrophin to regenerating mouse dystrophic muscle by muscle precursor cells. Proc. Natl Acad. Sci. USA 101, 35813586 (2004).

24. Torrente, Y., et al. Human circulating $\mathrm{AC} 133^{+}$stem cells replenish the satellite cell pool, restore dystrophin expression and ameliorate function upon transplantation in murine dystrophic skeletal muscle. J. Clin. Invest. 114, 182-195 (2004).

25. Tamaki. T. et al. Identification of myogenic-endothelial precursor cells in the interstitial spaces of skeletal muscle. J Cell Biol. 157, 571-577 (2002).

26. De Bari, C. et al. Skeletal muscle repair by adult human mesenchymal stem cells from synovial membrane. J Cell Biol. 160, 909-918 (2003).

27. Toma, J. G. et al. Isolation of multipotent adult stem cells from the dermis of mammalian skin. Nature Cell. Biol. 3, 778-784 (2001).

28. Rodriguez, A. M. et al. Transplantation of a multipotent cell population from human adipose tissue induces dystrophin expression in the immunocompetent mdx mouse. J. Exp. Med. 201, 1397-1405 (2005).

29. Dezawa, M. et al. Bone marrow stromal cells generate muscle cells and repair muscle degeneration. Science 309, 314-317 (2005).

30. Luo, D., Renault, V. M. \& Rando, T. A. The regulation of Notch signaling in muscle stem cell activation and postnatal myogenesis. Semin. Cell. Dev. Biol. 16, 612-622 (2005).

31. Leong, K. G. \& Karsan, A. Recent insights into the role of Notch signaling in tumorigenesis Blood 107, 2223-2233 (2005).

32. Lattanzi, L. et al. High efficiency myogenic conversion of human fibroblasts by adenoviral vector-mediated MyoD gene transfer. J. Clin. Invest. 101, 2119-2128 (1998).

33. Wright, W. E., Shay, J. W. \& Piatyszek, M. A. Modifications of a telomeric repeat amplification protocol (TRAP) result in increased reliability, linearity and sensitivity. Nucleic Acids Res. 23, 3794-4005 (1995).

34. Ouellette, M. M. et al. Subsenescent telomere lengths in fibroblasts immortalized by limiting amounts of telomerase. J. Biol. Chem. 275, 10072-10076 (2000).

35. Li, S. et al. Stable transduction of myogenic cells with lentiviral vectors expressing a minidystrophin. Gene. Ther. 12, 1099-1108 (2005).

36. Irizarry, R. A. et al. Exploration, normalization, and summaries of high density oligonucleotide array probe level data. Biostatistics 4, 249-264 (2003).

37. Liu, W. M. et al. Analysis of high density expression microarrays with signed-rank call algorithms. Bioinformatics 18, 1593-1599 (2002)

38. Tusher, V. G., Tibshirani, R. \& Chu,G. Significance analysis of microarrays applied to the ionizing radiation response. Proc. Natl Acad. Sci. USA 98, 5116-5121 (2001). 


\section{cell biology}

\section{Increased in DMD}

\begin{tabular}{|c|c|c|c|c|c|c|c|c|}
\hline ProbeSetID & Symbol & Gene & DMD3 & DMDA & MIX40Y & MIX78Y & CL9 & CLB \\
\hline 204470_at & CXCL1 & 2919 & 69 & 3201.9 & 372.7 & 175 & 119.7 & 196 \\
\hline 206336_at & CXCL6 & 6372 & 1655 & 1713.6 & 490.3 & 83.7 & 72.6 & 783 \\
\hline 211506_s_at & IL.8 & 3576 & $05 / .5$ & 719.9 & 53.8 & 7.2 & 141.7 & 379.7 \\
\hline 205207_at & IL6 & 3569 & 839.6 & 534.4 & 107.1 & 119.2 & 82 & 271.9 \\
\hline 221477_s_at & MGC5618 & 79099 & 3671 & 20995 & 303.4 & 455 & 687.4 & 407.6 \\
\hline 213524_s_at & Gos2 & 50486 & 3.1 & 1221.8 & 80.6 & 380.7 & 160.5 & 100.3 \\
\hline 209774_x_at & CXCL2 & 2920 & 3073 & 883.4 & 88.9 & 90.6 & 579 & 138.6 \\
\hline 204748_at & PTGS2 & 5743 & 5352 & 191.7 & 14.1 & 42 & 21.1 & 124 \\
\hline 209267_s_at & SLC39A8 & 64116 & 489.2 & 705.1 & 209.9 & 129.1 & 225.5 & 299.5 \\
\hline 204719_at & ABCA 8 & 10351 & 23912 & 117.19 & 158.9 & 264.7 & 221.3 & 119.2 \\
\hline 207850_at & CXCL3 & 2921 & $2332 ?$ & 487.3 & 175 & 91.1 & 121.3 & 251.4 \\
\hline 204731_at & TGFBR3 & 7049 & 22574 & 23668 & 272.4 & 389.7 & 193.9 & 160.4 \\
\hline 205404_at & HSD11B1 & 3290 & 2244.6 & 1286.4 & 37.6 & 752.4 & 79.1 & 322 \\
\hline 202644_s_at & TNFAIP3 & 7128 & 17994 & 584.5 & 137.7 & 873 & 248.9 & 167.1 \\
\hline 204358_s_at & FLRT2 & 23768 & 1183.6 & 845.2 & 116.3 & 248.3 & 150.9 & 59.5 \\
\hline 202994_s_at & FBLN1 & 2192 & 668.4 & 13515 & 81 & 173.1 & 44 & 21.2 \\
\hline
\end{tabular}

Genetitle

chemokine (C-X-C motif) ligand 1 (melanoma stimulat chemokine (C-X-C motif) ligand 6 (granulocyte chemo interleukin 8

interleukin 6 (interferon, beta 2)

hypothetical protein MGC5618

putative Iymphocyte G0/G1 switch gene

chemokine (C-X-C motif) ligand 2

prostaglandin-endoperoxide synthase 2

solute carrier family 39 (zinc transporter), member 8

ATP-binding cassette, sub-family $A$ (ABC1), member ?

chemokine (C-X-C motif) ligand 3

transforming growth factor, beta receptor III

hydroxysteroid (11-beta) dehydrogenase 1

tumor necrosis factor, alpha-induced protein 3

fibronectin leucine rich transmembrane protein 2

fibulin 1

\section{Decreasd in DMD}

\begin{tabular}{|c|c|c|c|c|c|c|c|c|c|}
\hline 202627_s_at & SERPINE1 & 5054 & 466.9 & 296.1 & 1089.6 & 2669 & 3270.4 & 6833.7 & serine (or cysteine) proteinase inhibitor \\
\hline 206116_s_at & TPM1 & 7168 & 446.1 & 501.2 & 2731.7 & 955.6 & 31544 & 5154.8 & tropomyosin 1 (alpha) \\
\hline 1555724_s_at & TAGLN & 6876 & 131.7 & 397.5 & 1640.5 & 1667.1 & 10482 & 47767 & transgelin \\
\hline 1558015_s_at & ACTR2 & 10097 & 912 & 117.9 & 849.6 & 484.9 & 10158 & 579.8 & ARP2 actin-related protein 2 homolog (yeast) \\
\hline 217818_s_at & ARPC4 & 10093 & 85.5 & 106.5 & 602 & 511.3 & 651.5 & 493.5 & actin related protein $2 / 3$ complex, subunit $4,20 \mathrm{kDa}$ \\
\hline 229802_at & WISP1 & 8840 & 75.7 & 64.3 & 765.7 & 128.9 & 625.1 & 28626 & WNT1 inducible signaling pathway protein 1 \\
\hline 208079_s_at & STK6 & 6790 & 67.8 & 202.1 & 1003.1 & 933.1 & 359.5 & 846 & serine/threonine kinase 6 \\
\hline 207016_s_at & ALDH1A2 & 8854 & 1.7 & 5.7 & 725.3 & 1014.2 & 960.7 & 140.6 & aldehyde dehydrogenase 1 family, member A2 \\
\hline 230425_at & EPHB1 & 2047 & 37 & 235.1 & 102.6 & 139.3 & 364.1 & 43.4 & EPH receptor B1 \\
\hline
\end{tabular}

Figure S1 Expression profiles of genes differentially expressed in two populations of Duchenne (DMD3 and DMDA) and of normal (MIX4OY

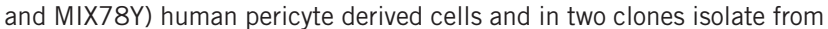
MIX78Y (CL9 and CLB) after IX PD in culture. Only those genes whose expression vary at least 3 fold among all the Duchenne and normal cells are shown. Values refer to the GCOS signal; black cells show transcripts with an "absent" call; signals for transcripts with a "present" call are showed in gradient coloured cells from blue (low abundant transcripts) to red (very high abundant transcripts). 

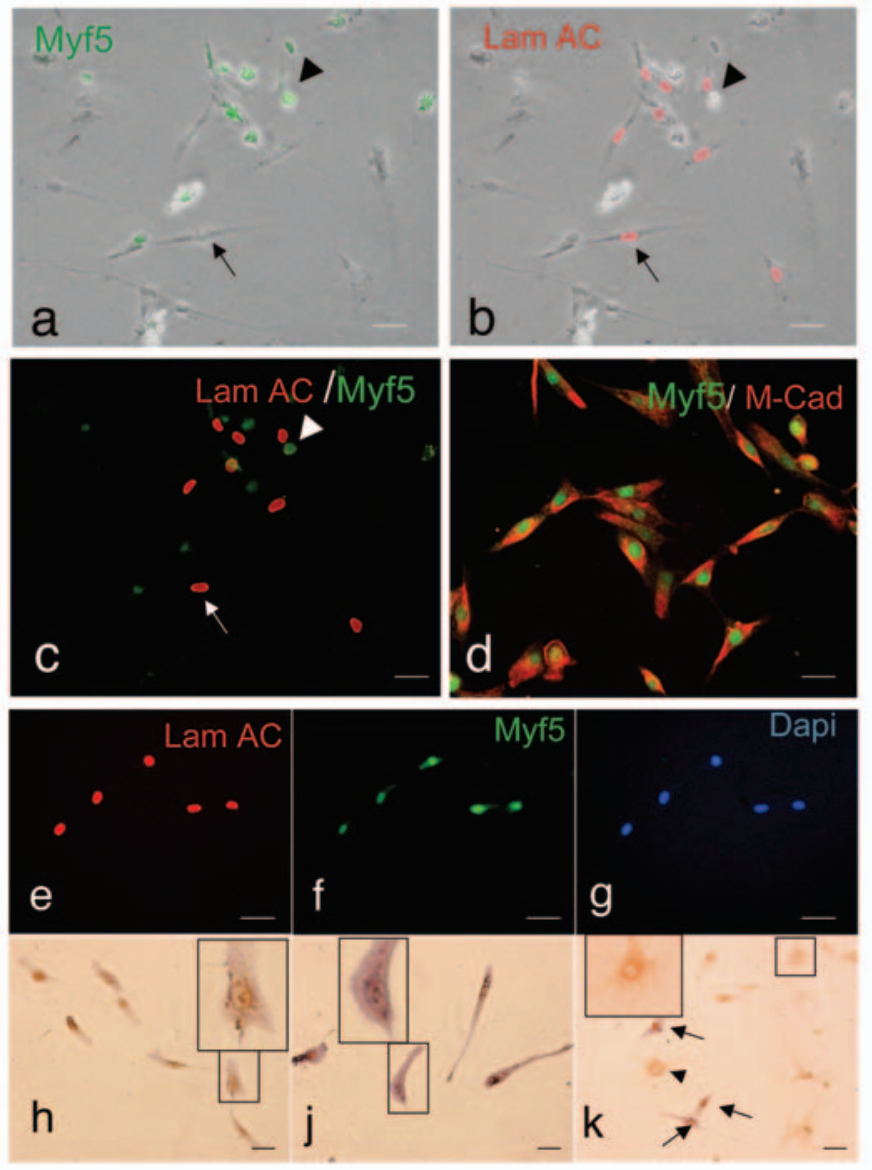

Figure S2 Isolation and cloning of human pericyte derived cells previously transplanted in dystrophic mouse muscle. (a-c) Three day culture of cells isolated from transplanted muscle. Human cells are labeled by anti-Lamin $\mathrm{A} / \mathrm{C}$ in red, while satellite derived cells are labeled by anti-Myf 5 antibody in green and by anti-M Cadherin in red (d). No double labeled cells were detected. $(\mathbf{e}, \mathbf{g})$ One clone of human (Lamin $\mathrm{A} / \mathrm{C}+$, red) cells that uniformly expresses Myf5 (green) indicating derivation of a myogenic precursor from transplanted human cells. (h,j) Two clones of human cells (Lamin A/C+, brown after peroxidase staining) which express low (h) of high (j) level of ALP (cytoplasmic staining). A mixed population of human ALP+ (arrow) and mouse ALP- cells (arrowhead) is shown in $\mathbf{k}$ for comparison. Bar $=20 \mu \mathrm{m}$. High magnification of cells indicated by arrows is shown in the inset. 

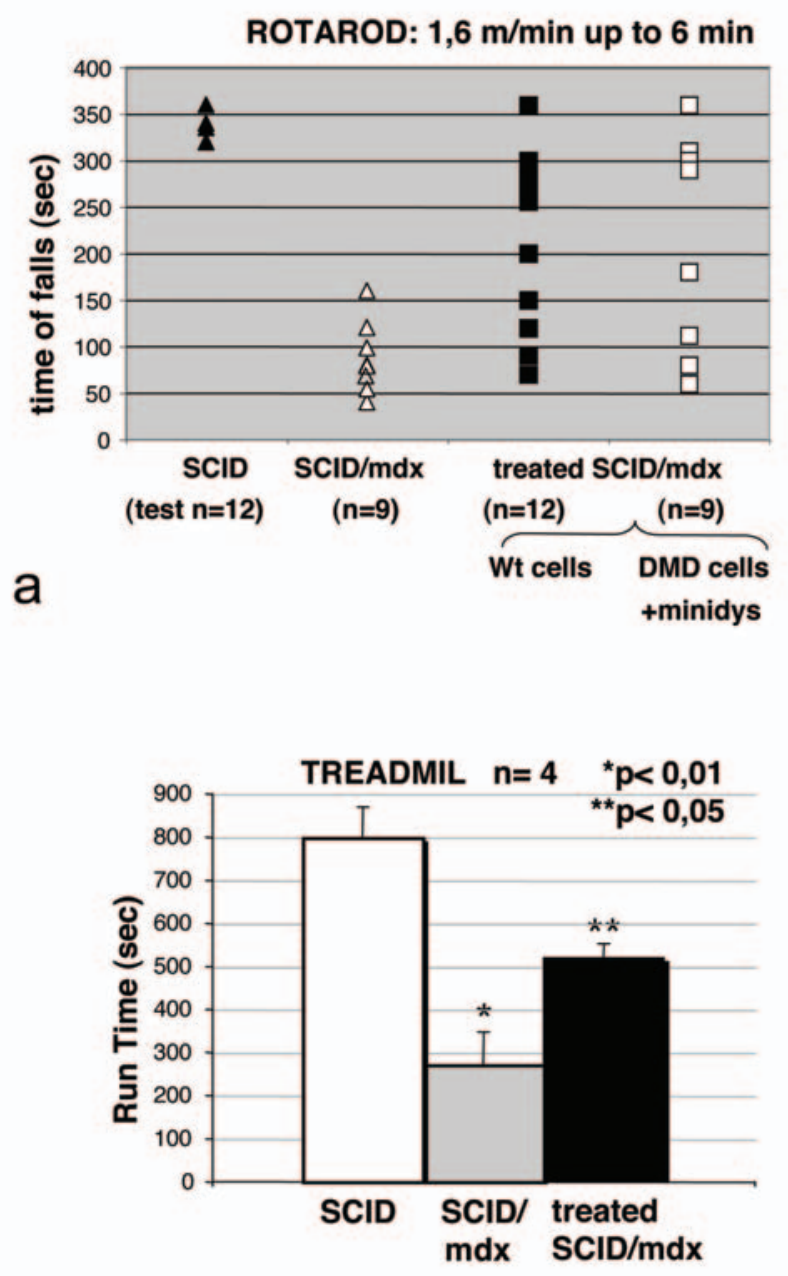

b

Figure S3 Exercise performance assessed by the rotarod test (a) and a runto-exhaustion protocol on a motorized treadmill (b). (a), SCID, SCID/mdx untreated mice and $\mathrm{SCID} / \mathrm{mdx}$ mice, transplanted with human perycytederived cells (either normal or DMD but genetically corrected with minidystrophin gene: mini-dys) were tested for functional recovery on a rotarod at a fixed speed of $1.6 \mathrm{~m} / \mathrm{min}$ up to 6 minutes. SCID mice felt only 3 times (after 320, 335 and 340 s) out of 12 tests (3/12) whereas untreated $\mathrm{SCID} / \mathrm{mdx}$ felt all the times, after running periods ranging from 30 to 160 $\mathrm{s}(9 / 9)$. SCID/mdx mice, transplanted with normal human perycyte-derived cells, felt 10 out of 12 times (10/12) and in 2 cases completed the test; in the other cases mice felt after periods ranging from 70 to $300 \mathrm{~s}$. SCID/ mdx mice, transplanted with DMD perycyte- derived cells, transduced with the lenti-vector expressing human mini-dystrophin, felt 7 out of 9 tests (7/9), after periods ranging between 60 and 310 s. (b), SCID, SCID/mdx untreated mice and $\mathrm{SCID} / \mathrm{mdx}$ mice transplanted with human perycytederived cells were subjected to a run-to-exhaustion protocol on a motorized treadmill as described in Materials and Methods; $n=3$ for each group; * $p<$ 0.001 compared to corresponding SCID values; ${ }^{* *} p<0.005$ compared to corresponding $\mathrm{SCID} / \mathrm{mdx}$ untreated $(\mathrm{SCID} / \mathrm{mdx}$ ) values. 


\section{Supplementary Methods for NCB-CO9476E}

Satellite cell and fibroblast cultures: Briefly, muscle fragments were digested with $2 \%$ (w/v) collagenase II (Gibco BRL) for $60 \mathrm{~min}$ at $37^{\circ} \mathrm{C}$. Digested cells were discarded and fragments were incubated again with $0.05 \%$ trypsin (Gibco BRL) for 15 min at $37^{\circ} \mathrm{C}$ with gentle agitation. After the incubation, isolated cells were collected and fragments were incubated again until the whole tissue was digested (usually three times). The isolated cells were pooled, centrifuged and resuspended in DMEM supplements with $20 \%$ pre-screened FCS, $1 \%$ gentamycin, and plated onto collagen coated dishes at a density of $10^{4}$ cells $\mathrm{x} \mathrm{cm}^{2}$. Contamination by non myogenic cell was reduced by pre-plating the cell suspension onto plastic dishes where fibroblasts tend to adhere more rapidly. Differentiation was induced shifting the medium to DMEM supplemented with $2 \%$ horse serum. Fibroblasts were prepared by subculturing cells outgrown from an explant of a dermis biopsy and grown in DMEM supplemented with $20 \%$ FCS.

Flow cytometry and sorting: Three normal and three DMD biopsies were finely minced and digested with collagenase/dispase (Sigma) digestion $\left(0,8 \mathrm{IU} / \mathrm{mg}\right.$ for $30 \mathrm{~min}$ at $\left.37 \mathrm{C}^{\circ}\right)$. The cell suspension was filter to remove tissue debris. Isolated cells were harvested and resuspended in 1 $\mathrm{ml}$ of a solution containing $5 \mu \mathrm{g} / \mathrm{ml}$ propidium iodide (Sigma) in PBS (Gibco Brl) and incubated with specific antibodies for 1 hour at $4{ }^{\circ} \mathrm{C}$; after PBS washing cells were fixed in $2 \%$ PFA before FACS analysis. Cell analysis was performed on at least 10.000 events for each sample and determined using a FACScalibur flow cytometer (Becton Dickinson) equipped with an argon laser emission of $488 \mathrm{~nm}$. FITC was identified by using a 530 band pass filter. The analysis was performed using CELLQUEST software (Becton Dickinson). A primary gate based on physical parameters (forward and side light scatter, FSC and SSC, respectively) was set to exclude dead cells or small debris. The background level was estimated by omitting the primary antibody.

Before sorting, cells were incubated with sheep anti-human Alkaline phosphatase (Biogenesis) and PE-conjugated mouse anti-human CD56 (Miltenyi Biotec) antibodies according to the manufacture's recommendations. 
Differentiation assays: Co-cultures were shifted to differentiation medium (DMEM supplemented with $2 \%$ horse serum). After 7 days cultures were stained with antibodies against striated myosin (MF20) and X-Gal. Percentage of myogenic differentiation was calculated by counting the number of LacZ+ nuclei within myosin positive cells as percentage of total LacZ+ nuclei. Biochemical differentiation was confirmed by RT-PCR using human specific oligonucleotides for MyoD (FW: CGATATACCAGGTGCTCTGAGGG; REV: GGGTGGGTTACGGTTACACCTGC).

Immunofluorescence: Sections were incubated with primary antibodies overnight at $4^{\circ} \mathrm{C}$ in PBS supplemented with 1\% BSA and 0.2\% TritonX-100. For the anti-Myf5 and M-Cadherin antibodies (see below) sections were fixed in acetone for $10 \mathrm{~min}$ at $-20^{\circ} \mathrm{C}$ and antibody incubation was for $1 \mathrm{~h}$ at RT. For the M-Cadherin antibody, all solutions also contained $10 \mathrm{mM} \mathrm{Ca}{ }^{2+}$. All sections were washed $\mathrm{x} 3$ in PBS and incubated with $10 \%$ donkey serum for 30 min at RT before the addition of the appropriate Alexa 488 or Alexa 594 or Alexa 647 conjugated donkey secondary antibodies. Background staining of anti-mouse secondary antibodies was reduced by addition of $0.1 \%$ mouse serum to the secondary antibody mixture. In some experiments we used biotinylated secondary antibody from DAKO and processed according to the standard procedures of VECTASTAIN Elite ABC kit (Vector Laboratories). After three final washes, the cover slips were mounted on glass slides using mowiol in PBS and analyzed under a fluorescent microscope.

Antibodies: The following antibodies were used in this study: anti-dystrophin monoclonal antibody Dys1, Dys2 and Dys3 (Novocastra) at 1:125 dilution; anti-laminin polyclonal rabbit antibodies (Sigma) at 1:100 dilution; MF20 monoclonal antibody at 1:5 dilution, anti-smooth alpha actin monoclonal at 1:300 dilution and anti-desmin rabbit polyclonal at 1:50 from Sigma, anti-Pax7 from the hybridoma bank at 1:3 dilution, anti-human lamin A/C 1:300 monoclonal from Novocastra, anti-NG2 rabbit polyclonal at 1:250 (Chemicon), anti-PDGF receptor beta rabbit polyclonal at 1:500 (from Cell Signaling Technologies); anti-M Cadherin goat polyclonal at 1:30 dilution and anti-Myf5 rabbit polyclonal at 1:200 dilution were from Santa Cruz; anti-PECAM rat 
monoclonal (a gift from Elisabetta Dejana) at 1:2 dilution. For FACS analysis the following antibodies were used CD44, CD34, CD45, CD49b, CD117, CD62L,CD63,CD90 from BD Biosciences, CD31, CD13, CD106 from ID labs inc, CD146 from Biocytes, CD105 from R\&D System and CD56 from Miltenyi Biotec. Secondary antibodies were from Molecular Probes.

Gene Expression Profiling and data analysis: Total cellular RNA was isolated from cell populations (two DMD patients, age 3 and 6; two healthy individuals, age 15 and 40 and from two clones of the 40 years old individual) using RNeasy RNA isolation kit (Qiagen, Valencia, CA) following manufacturer's recommendations. Disposable RNA chips (Agilent RNA 6000 Nano LabChip kit) were used to determine the concentration and purity/integrity of RNA samples using Agilent 2100 bioanalyzer. cDNA synthesis, biotin-labeled target synthesis, HG-U133 plus 2.0 GeneChip (Affymetrix, Santa Clara, CA) arrays hybridization, staining and scanning were performed according to the standard protocol supplied by Affymetrix. The amount of a transcript mRNA (signal) was determined by the Affymetrix GeneChip Operative Software (GCOS) 1.2 absolute analysis algorithm as already described ${ }^{36}$. All expression values for the genes in the GCOS absolute analyses were determined using the global scaling option. Alternatively, probe level data were converted to expression values using robust multi-array average (RMA) procedure ${ }^{37}$. Perfect Match (PM) values were background adjusted, normalized using invariant set normalization, and $\log$ transformed. The RMA generated data were uploaded onto GeneSpring ${ }^{\mathrm{TM}}$ software version 7.2 using the $\log 2$ transformation procedure. A "per chip" and a "per gene" normalization were achieved by dividing each signal for the 50.0th percentile of all above -10 signals in that sample and by the median of its values in all samples. A low-level filter in GeneSpring ${ }^{\mathrm{TM}}$ filtered out all those probe sets called "Present" in less than $10 \%$ of samples or whose normalized expression levels were always between 0.5 and 2 across all of the samples. For supervised analyses an initial filtering procedure was applied in order to select transcripts showing a change call "I" or "D" in at least the $90 \%$ of the pair wise comparisons performed using the GCOS comparison algorithm ${ }^{38}$. Then, supervised analyses were performed using an ANOVA test (Welch t-test at a confidence level of 
0.005) with the Benjamini \& Hochberg correction of the family-wise error rate (FWER). Hierarchical agglomerative clustering was performed in GeneSpring ${ }^{\mathrm{TM}}$ using Pearson's correlation coefficient and average-linkage as distance and linkage methods.

Exercise protocols: Control, SCID $(\mathrm{n}=4), \operatorname{SCID} / \mathrm{mdx}$ untreated mice $(\mathrm{n}=3)$ and $\mathrm{SCID} / \mathrm{mdx}$ mice, transplanted with human pericyte derived cells (normal, $\mathrm{n}=4$ and DMD, genetically corrected, $n=3$ ) were tested for functional recovery on a rotarod at a fixed speed of 1.6 $\mathrm{m} / \mathrm{min}$ up to 4 minutes. The number of falls during this period was recorded. For the treadmill test, mice (3 treated and 3 untreated SCID/mdx and 3 non dystrophic SCID) were adapted to the procedure $(10 \mathrm{~min} /$ day; $0.3 \mathrm{~km} / \mathrm{h})$ for $1 \mathrm{wk}$ before beginning the exercise training protocol. Treated and untreated mice were tested at a treadmill speed of $0.3 \mathrm{~km} / \mathrm{h}$. Treated animals were trained during the transplantation period and tested 21 days after the last transplantation. Control animals of the same age were tested at the same time. 